\title{
A constitutive model for soft clayey rocks that includes weathering effects
}

\author{
N. PINYOL*, J. VAUNAT* and E. E. ALONSO*
}

\begin{abstract}
Microstructural and mineralogical observations of claystones reveal the presence of clay aggregates bonded by a skeleton of inert minerals such as calcium carbonate. The behaviour of these natural materials evolves from a rock-like behaviour, when undisturbed, to clay-like soil when weathered or when subjected to straining. A model has been developed to simulate the constitutive behaviour of these transitional materials. Following the proposal made by Vaunat \& Gens, the material is conceived as a composite medium made of a clay matrix and a quasibrittle bonding microstructure. The basic model has been modified and extended to reproduce the expansive behaviour of the clay matrix, a fundamental aspect to simulate weathering effects, induced largely by drying-wetting cycles. The clay matrix reacts to stress and suction changes, whereas the bond component is not affected by suction changes. An elasto-plastic double-structure model for expansive clay soils describes the clay matrix. The bonding structure follows a damage model. The interaction between the two constitutive models derives from strain compatibility conditions and energy considerations. The model performance is first illustrated by means of a sensitive analysis that explores the effect of initial bond strength, bond damage rate, bonding concentration, and wetting-drying cycles. Simple stress paths (uniaxial deformation; triaxial compression) are used to highlight the features of the formulation and the role of significant parameters. Some published tests are also reproduced with the model. They have been selected to show some relevant features of evolving soft clay rocks: stiffness and strength degradation during loading and enhanced rebound during unloading, and the effect of drying-wetting cycles on subsequent stiffness and strength degradation.
\end{abstract}

KEYWORDS: constitutive relations; expansive soils; plasticity; soft rocks; suction
Les observations microstructurales et minéralogiques de l'argilite ont révélé la présence d'agrégats argileux cimentés par un squelette de minéraux inertes tels que le carbonate de calcium. Le comportement de ces matériaux naturels évolue, d'un comportement proche d'une roche (lorsqu'ils laissés tels quels) au comportement d'un sol de type argileux (lorsqu'ils sont dégradés ou soumis à des contraintes). On a développé un modèle pour simuler le comportement constitutif de ces matériaux de transition. Suite à la proposition de Vaunat \& Gens, on considère que le matériau est un milieu composite fait d'une matrice argileuse et d'une microstructure de cimentation quasifragile. Le modèle de base a été modifié et étendu pour reproduire le comportement expansif de la matrice argileuse, un aspect fondamental pour simuler les effets de dégradation essentiellement induits par les cycles de séchage-mouillage. La matrice argileuse réagit aux changements de contrainte et d'aspiration tandis que la composante de cimentation n'est pas affectée par les changements d'aspiration. On peut décrire la matrice argileuse des sols argileux expansifs à l'aide d'un modèle à doublestructure élasto-plastique. La structure de cimentation, quant à elle, utilise un modèle de détérioration. L'interaction entre les deux modèles constitutifs provient des conditions de compatibilité de contrainte et des considérations énergétiques. La performance des modèles est d'abord illustrée par l'intermédiaire d'une analyse de sensibilité qui explore l'effet de la résistance de la cimentation initiale, le taux de détérioration de la cimentation, la concentration de la cimentation et les cycles de séchagemouillage. On a utilisé des chemins de contraintes simples (déformation uniaxiale, compression triaxiale) pour souligner les caractéristiques de la formulation et le rôle des paramètres significatifs. Outre le modèle, cet article reproduit des essais publiés. Ceux-ci ont été sélectionnés pour montrer certaines caractéristiques pertinentes des roches argileuses fermes évolutives : dégradation de la fermeté et de la résistance lors de la compression et augmentation lors de la décompression par effet de rebond ainsi que l'effet des cycles de séchage-mouillage sur la dégradation ultérieure de la fermeté et de la résistance.

\section{INTRODUCTION}

'Clayey rocks' is a general term for a wide variety of materials that include clay shales, marls, sulphate-bearing claystones, and many types of indurated overconsolidated clay of pre-Pleistocene age. They are 'soft' rocks in the sense that their unconfined compression strength is moderate or low, typically smaller than $30 \mathrm{MPa}$. They are common in nature, and are often present in civil engineering works.

Manuscript received 31 May 2006; revised manuscript accepted 14 December 2006.

Discussion on this paper closes on 1 August 2007, for further details see p. ii.

Department of Geotechnical Engineering and Geosciences, UPC, Barcelona, Spain.
Examples of distribution of clay shales in North America and Italy are given by Hsu \& Nelson (1993) and Bertuccioli \& Lanzo (1993). A characteristic feature of these materials is that they weather or degrade when they are exposed to stress or environmental conditions that differ from their undisturbed state. The term 'weathering' implies mechanical, physical and chemical changes, whereas 'degradation' usually refers to a loss of mechanical competence. In their undisturbed state the type of clayey rocks considered in this work are in an intermediate stage in the diagenetic processes that change clay sediments into indurated rocks. Processes leading to rock formation include the increase in confining stress due to increased depth of burial, and the cementation of minerals that precipitate from solution in the pore water. Mineral changes may also occur. The precipitated minerals 
add strength and stiffness to the material. These precipitated minerals are conceived as relatively rigid and brittle materials if they are compared with the mechanical properties of the clay matrix.

The two components of the clayey rock just mentioneda rigid but brittle bonding and a more deformable clay matrix - are the starting point for the constitutive model described in the paper. The geometrical arrangement of clay matrix components (clay platelets tend to stack in larger units or aggregates), cementing minerals such as carbonates, and residual pore space provides interesting information for modelling purposes, because it may orient some decisions concerning the basic hypothesis of the constitutive framework, as mentioned later.

A conceptual model of the microstructural nature of a mudstone from eastern France is discussed by Sanmartino (2001), on the basis of the analysis of SEM micrographs. Two stratigraphic levels, one rich in carbonates and the other dominated by clay minerals, were examined. The microstructure of the clay-rich horizon showed a clay matrix that surrounds isolated quartz grains and carbonate crystals. In the carbonate-rich zone the carbonate minerals are uniformly present within the clay matrix. The observation that increasing carbonate content leads to increased strength is quite common: one example is provided by Hsu \& Nelson (1993) when they report the strength of Taylor and Austin chalk formations in Texas.

Engineering works such as excavations have two distinct effects on the exposed materials: a reduction in confining stress (and possibly an increase in deviatoric stress components), and a cyclic change in humidity due to atmospheric interaction. Field profiles of the water content of exposed clayey rock formations often show the presence of a welldefined 'weathering front'. Below the front the water content remains at its undisturbed low value. Above the front the material evolves rapidly into a clay formation with a substantial increase in water content. Increasing the water content (which is also an indication of increased porosity) leads to a rapid reduction in mechanical properties. Two examples are given in Figs 1 and 2. Fig. 1 shows the unconfined compression strength measured in rock cores taken in boreholes located in the floor of Lilla Tunnel (Tarragona, Spain). Lilla Tunnel is excavated in early Eocene argillaceous rock containing anhydrite and gypsum veins. The plot shows the rapid reduction in strength as the water content increases.

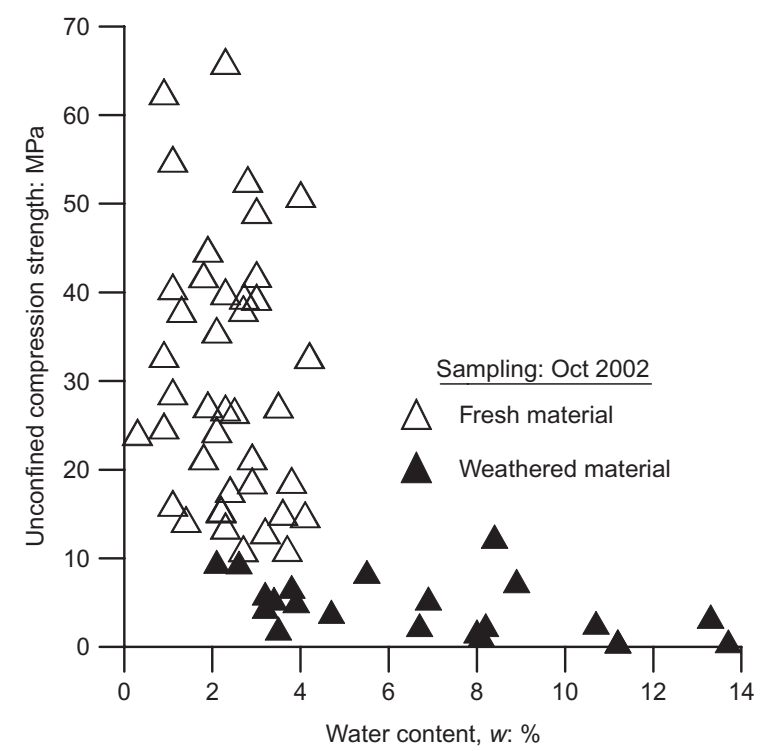

Fig. 1. Variation of unconfined compression strength with water content of Lilla claystone
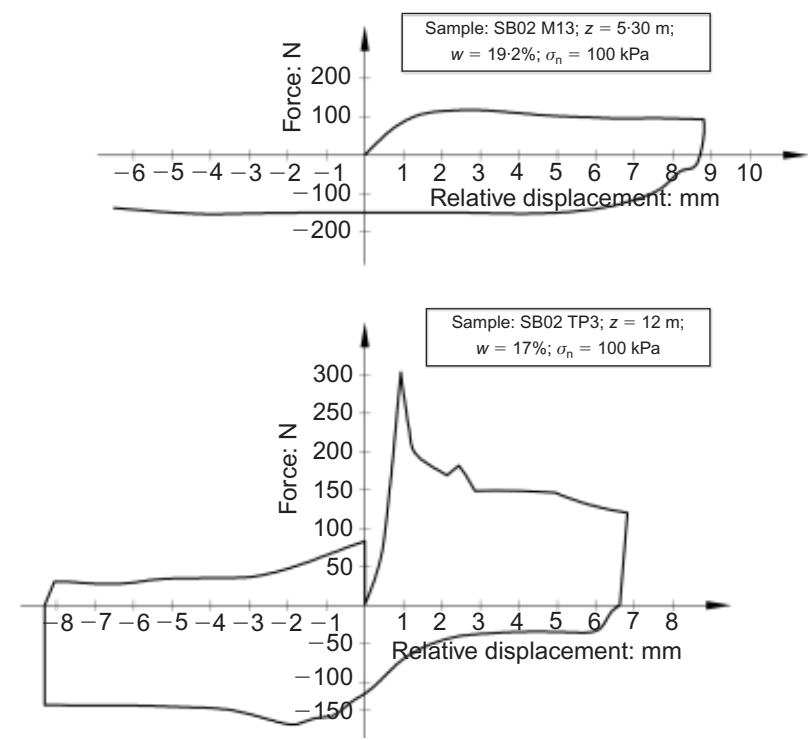

Fig. 2. Curves of force against relative displacement measured in two cores from El Bierzo tertiary clay formations

Visual identification of cores as 'fresh' or weathered is also shown in the figure. A description of this case is given in Alonso \& Berdugo (2005).

The loss in strength is associated with a parallel reduction of brittleness. This is shown in Fig. 2, which compares two slow direct shear tests performed on cores recovered from red continental low-plasticity Tertiary clays from El Bierzo, Spain. The two specimens were tested under identical confining stresses $(100 \mathrm{kPa})$. The unweathered core, with a water content of $17 \%$, was taken at a depth of $12 \mathrm{~m}$, and exhibited a marked brittle behaviour. A shallower specimen, having a small increase in water content $(2 \cdot 2 \%)$, reacted as a ductile material. Its shear strength was close to the 'residual' strength determined in the shear box, after a full shearing cycle. The strength envelopes determined for this material are shown in Fig. 3. Peak strengths show a considerable scatter. 'Residual values' as determined after a cycle of shear stress applications show a marked loss in strength, but the point to note here is that there are two alternative circumstances leading to the low 'residual' strength: either a shear straining of the undisturbed material, or a natural weathering, which resulted in a (relatively small) increase in water content. The identification of these apparently separate mechanisms is not so simple in this case, however, because

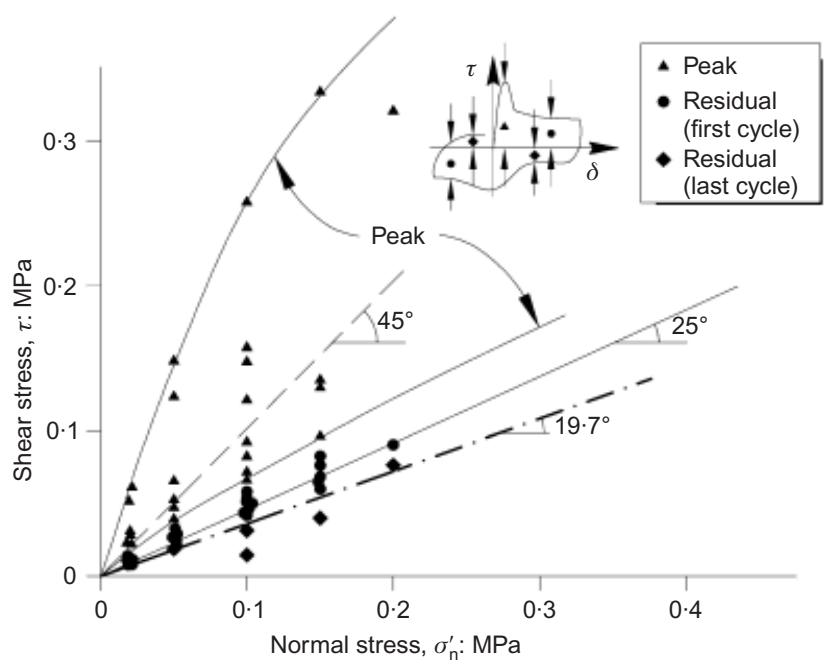

Fig. 3. Strength envelopes for El Bierzo tertiary clay 
the cores were recovered from a natural slope with symptoms of shallow instability, and therefore some previous natural straining of the upper core specimen cannot be disregarded in this case.

This paper describes a constitutive model inspired by the observed features of clayey rocks, as outlined above. Specific attention has been given to the simulation of weathering effects and, in particular, to two important mechanisms that are believed to control, in practice, the loss of mechanical properties of these materials: the straining associated with stress changes, and the wetting-drying cycles imposed by atmospheric action. Other effects mentioned in the literature (Mitchell, 1976) that contribute to weathering (thermal straining, crystal dissolution or precipitation, chemical reactions) are not considered here. Before the model is described, some additional features of clay rock behaviour, which justify some modelling hypotheses, are described in the next section. In a second part of the paper, the model performance is presented and compared with some selected laboratory tests.

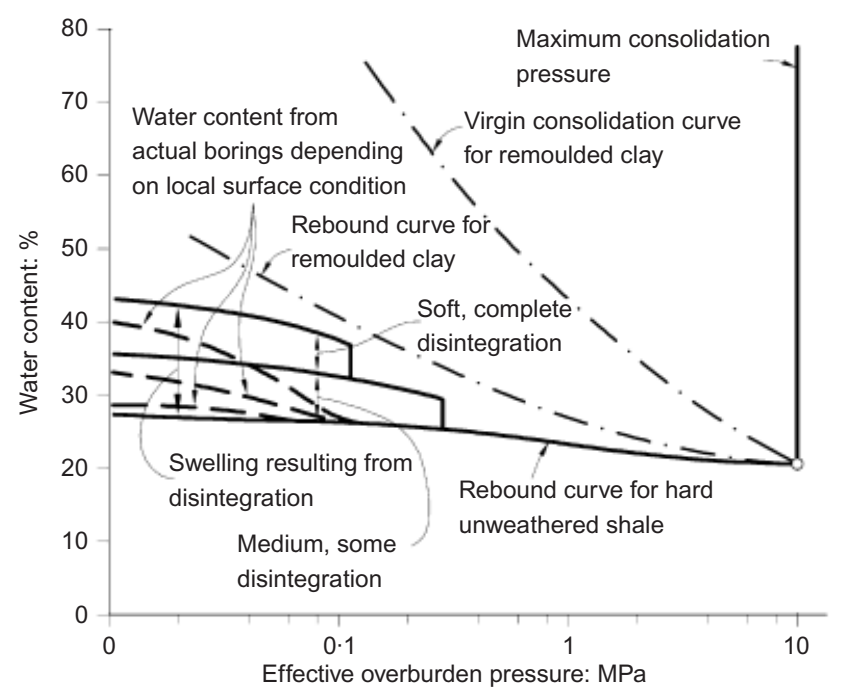

Fig. 4. Geological history of Bearpaw clay shale (Bjerrum, 1967)

\section{ADDITIONAL FEATURES OF CLAYEY ROCK BEHAVIOUR \\ The consequences of bonding under stress}

Bjerrum (1967), in his study of montmorillonitic Bearpaw clay shales $\left(w_{\mathrm{L}}=90-120 \%\right)$, provided an interpretation for the observed water content of recovered specimens. When water content is plotted against the calculated effective overburden stress for each specimen, a 'rebound' or 'unloading' curve should be obtained (Fig. 4), because the region was subjected to high $(10 \mathrm{MPa})$ preconsolidation stress before being unloaded.

Specimens from different locations were plotted on different rebound curves. Bjerrum attributed this behaviour to a varying degree of shale 'disintegration'. Hard unweathered specimens maintain the lowest water contents. Increasing degradation (rebound curves are shown in Fig. 4) lead to increasing water contents. The loading-unloading curve for the remoulded clay is also shown in Fig. 4. The field curve of soft clay shale tends toward the unloading or swelled curve of the remoulded structure-free specimen. Bjerrum (1967) attributed the swelling of the unloaded shale to the release of the 'locked-in strain energy'. The expression provides a clue to the reason for swelling and damage of clay shales. If a clay soil, in the process of diagenesis, becomes bonded when under stress, it has the potential to swell if the stress is removed. It all depends on the relative intensity of the stress changes induced by unloading, and on the internal bond strength.

The idea is illustrated in Fig. 5. A clay matrix, organised in aggregates, is first compressed and then cemented under stress. The associated changes in void ratio are sketched in the same figure. Then stress changes induced by unloading damage the cementing bonds to some extent, and allow clay aggregates to expand. Further reloading may contribute to additional bond damage.

Swelling and swelling-induced damage are not the exclusive behaviour of clay rocks that contain active clay minerals (such as Bearpaw shale). In fact, clays of any plasticity may behave in a qualitatively similar manner. Even granular soils cemented under load may exhibit swelling if unloaded. The energy stored in hertzian contacts between grains may be released if the bonds are broken. Such behaviour was observed in some elegant tests reported by Fernández \& Santamarina (2001).
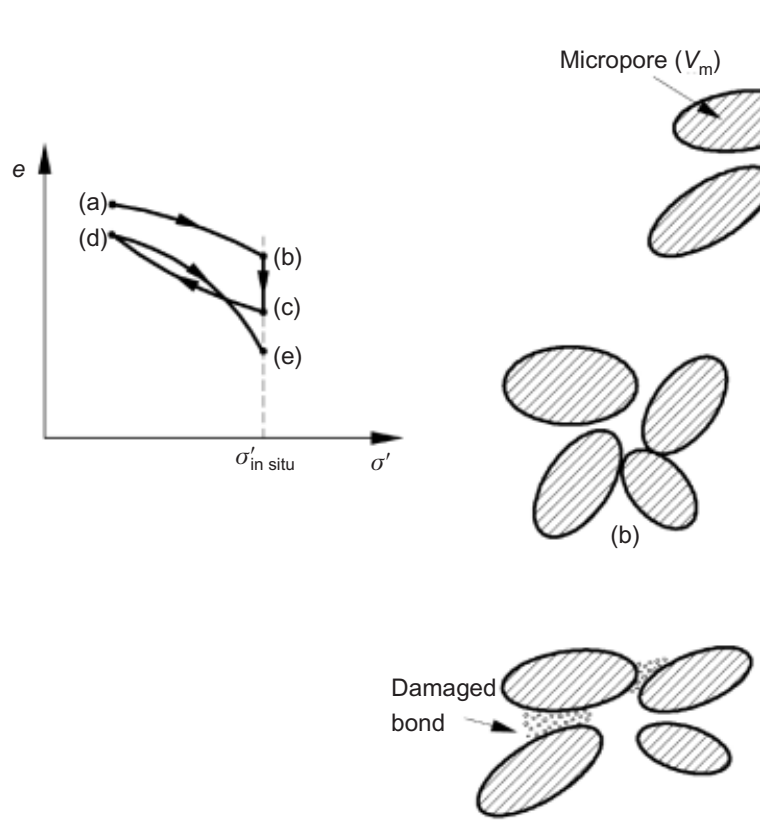

(b)

(d)

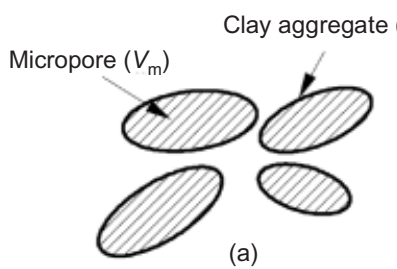

(a)

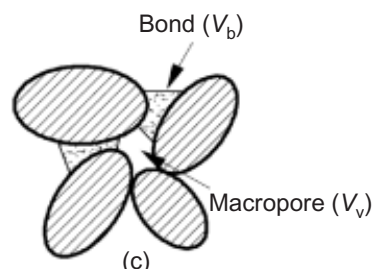

(c)

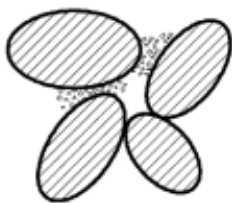

(e)

Fig. 5. Interpretation of diagenesis process and structural effects of an unloading-reloading cycle on a clayey rock 
The effect of loading and unloading cycles

Besides the natural loading and unloading cycle implied by overconsolidation, an additional unloading is normally associated with core boring operations. When load is then imposed in a test, the material has already experienced a particular stress path history. In practice, excavation followed by foundation construction imposes an unloading-loading cycle. Tunnelling excavation and lining leads, in a similar way, to stress reversals. It is therefore appropriate to investigate the response of bonded clay shales to loading-unloading cycles. One interesting example is the behaviour of Laviano 'scaly' clay shale, a highly tectonised material with moderate expansive behaviour, described by Picarelli (1991). A sequence of applied loading-unloading cycles under oedometric conditions led to a progressive loss of material stiffness during cycle applications. This behaviour is consistent with the concept of destructuration suffered by the clay when loaded above a certain limit and the subsequent release of swelling potential during unloading. According to Kavvadas (2000), the swelling index is an indicator of the amount of structure in soils, because the reconstituted material is expected to swell more than the natural one.

A different behaviour was observed for Todi clay (Calabresi \& Scarpelli, 1985), a heavily overconsolidated and intensively fissured lacustrine clay. The reported behaviour (Fig. 6) will later be compared with model calculations. During first loading, a compression curve similar to that of Laviano clay was observed. However, during the subsequent unloading, a very high swelling strain occurred and the void ratio increased above its initial value. During the second loading cycle, the sample experienced first a stiff response similar to that of the intact material, but it apparently reached a yield point at a lower value, indicating that some destructuration had previously occurred. The slope of the $\mathrm{NC}$ line is now higher than the slope of the intact material, but still lower than the slope of the reconstituted clay. The

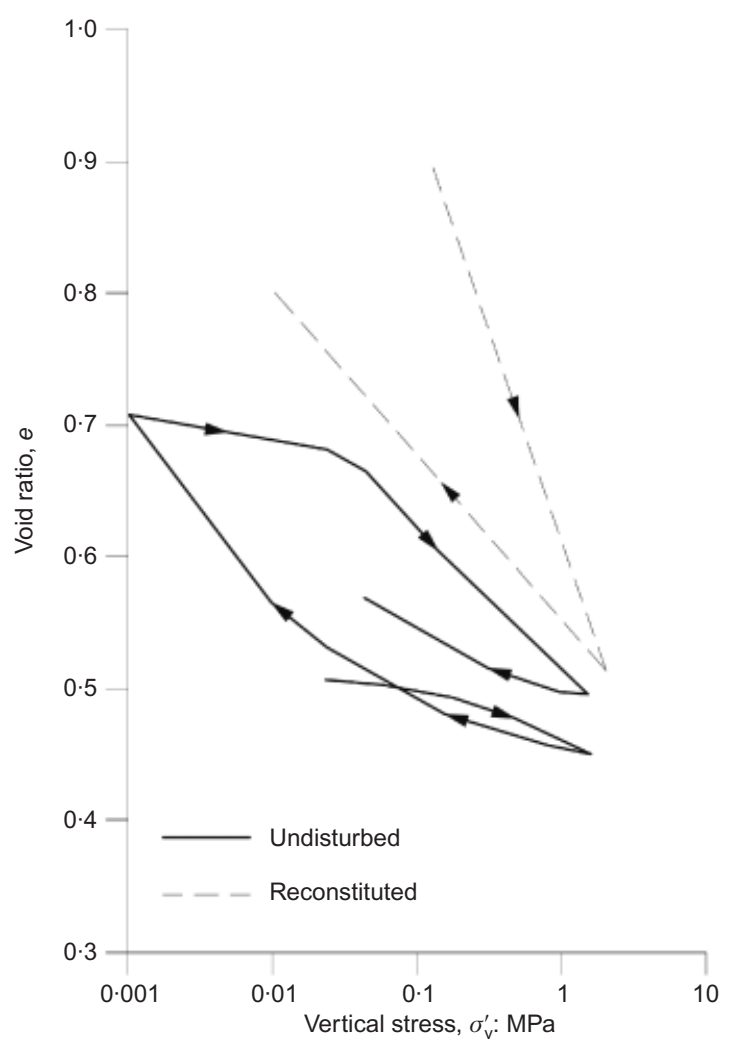

Fig. 6. Compression oedometer tests on Todi clay (Calabresi \& Scarpelli, 1985) swelling coefficient during the second unloading path lies between values of the intact and the destructured material. This response is attributed to a partial damage of bonds, which removes the interparticle forces that prevent swelling and releases the expansive potential of clay minerals.

\section{Drying-wetting cycles}

Changes in relative humidity $(\mathrm{RH})$, as well as rainfall and evapotranspiration phenomena, lead, in many engineering situations, to the application of suction cycles to the exposed material. Even in tunnelling works, protected from rainfall and transpiration phenomena, changes in RH are significant. Records of relative humidity measured in Lilla Tunnel (data on the variation of strength of Lilla claystone with water content were given in Fig. 1) over 8 months indicated RH values ranging between $93 \%$ and $20 \%$. Similar records for the Orange-Fish tunnel in South Africa have been given by Olivier (1987). RH changed from full saturation to values close to $55 \%$. In this case, the rock excavated was a carboniferous expansive mudrock. Olivier (1987) reported the strong effect of full wetting-air drying cycles on unconfined specimens. Some specimens were described as broken after two wetting-drying cycles.

Wong (1998) performed drained triaxial tests on specimens of intact La Biche shale, a medium-plasticity $\left(w_{\mathrm{L}}=\right.$ 44.6-45.8\%) compact shale from western Canada, previously subjected to free or semi-confined swell. He also investigated the effect of swelling under different salt concentrations of the water added in swelling tests. Fig. 7(a) illustrates the behaviour of the intact material. Increasing the confining stress leads to a progressive ductility of the shale. Once the specimens are swelled under a $50 \mathrm{kPa}$ vertical

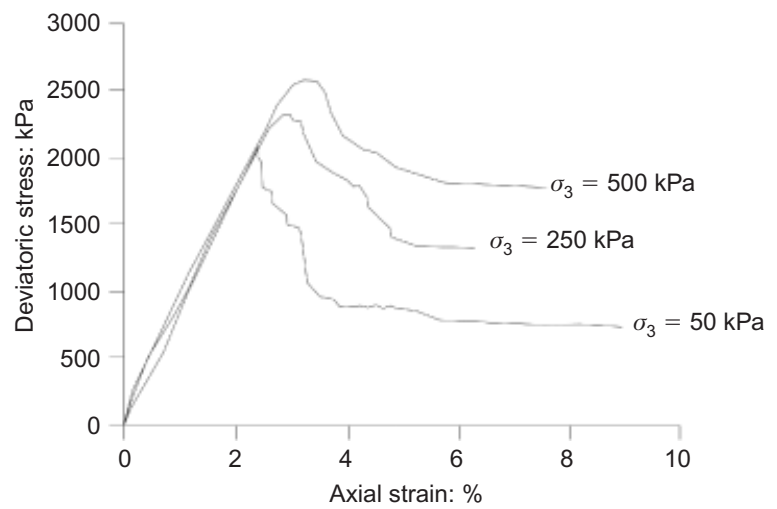

(a)

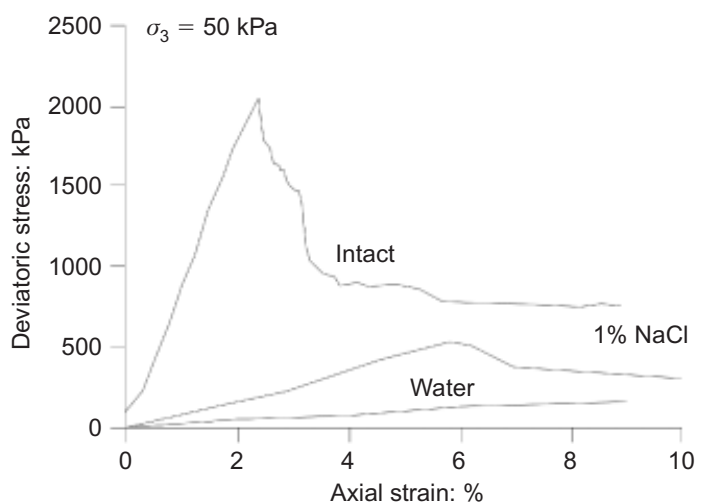

(b)

Fig. 7. Drained triaxial tests on: (a) intact La Biche shale: (b) swollen specimens at a confining stress of $50 \mathrm{kPa}$ (after Wong, 1998) 
stress, a profound degradation in strength and stiffness is observed in the subsequent triaxial test (Fig. 7(b)). Application of pure water (during swelling) leads to the maximum structural breakdown. When swelling is restricted by using a salt concentration in the water, or by imposing a constant vertical stress during wetting, the degradation is also limited, and the shale may retain some brittleness under the set of confining stresses investigated.

Similar results were obtained by Rampello (1991), who investigated the effect of a single desiccation-resaturation cycle on the subsequent triaxial response under triaxial testing of Todi Clay.

In all the tests mentioned, the strength of the weathered material falls well below the 'end of test' strength values recorded on undisturbed specimens.

\section{Summary of results}

The described features can be summarised as follows:

(a) When bonding occurs under confining stress, a potential expansibility is built into clayey rocks.

(b) Changes in stress may damage the bonding and allow the release of the swelling potential. Unloading-loading cycles are common in engineering works, and they contribute to accumulated bond damage and soil swelling. Some experiments indicate that the damaged material progressively approaches the state of the remoulded material, although this is not always the case.

(c) Wetting-drying cycles are also expected in exposed surfaces of clayey rocks. Experiments indicate that suction cycles are capable of inducing substantial damage in bonded clayey rocks.

\section{MODEL DESCRIPTION}

The clayey soft rock is conceptualised as a composite material made of a clay matrix and a distributed network of bonds, which partially occupy the macropores of the clay matrix (Vaunat \& Gens, 2003). The clay matrix has its own structure. Following accepted ideas of clay particle association in clays (Gens \& Alonso, 1992), clay platelets are stacked in aggregates that may swell or shrink. A description of clay stacks in shaly rocks and clay shales is given by Pye \& Krinsley (1983) and Seedsman (1987). Volume changes of these stacks (which may integrate thousands of individual clay sheets) are thought to disrupt the bonded structure of the rock. The structure of the clay matrix is conveniently described as a micro-macro structure. 'Micro' refers to the porosity inside the clay aggregates; 'macro' describes the void space between clay aggregates. The 'macro' space includes open voids available for fluid transfer, and the volume occupied by the cementation minerals (bonds). Two types of pore coexist in the medium: the small pores inside the aggregates; and the relatively large pores between aggregates. A sketch of the model components is given in Figs 5(a) and 5(c).

\section{Topologic considerations and strain compatibility}

In the reference volume (Fig. 5), the following volumetric variables may be defined.

$V$ total volume

$V_{\mathrm{SM}}$ solid volume of (clay) matrix

$V_{\mathrm{b}}$ solid volume of bond material (it is assumed to be nonporous)

$V_{\mathrm{v}}$ volume of macropores

$V_{\mathrm{m}}$ volume of micropores
The following relation holds:

$$
V=V_{\mathrm{sM}}+V_{\mathrm{b}}+V_{\mathrm{v}}+V_{\mathrm{m}}
$$

The total volume of solids, $V_{\mathrm{s}}$, is

$$
V_{\mathrm{s}}=V_{\mathrm{sM}}+V_{\mathrm{b}}
$$

It is convenient, in order to define later strains, to consider the existing volume between clay aggregates, $V_{\mathrm{M}}^{*}$. It includes the bond volume and the volume of macropores:

$$
V_{\mathrm{M}}^{*}=V_{\mathrm{b}}+V_{\mathrm{v}}
$$

A change in $V_{\mathrm{M}}^{*}$ is a measurement of the relative motion of the clay aggregates. The asterisk $(*)$ is introduced to indicate that $V_{\mathrm{M}}^{*}$ may be considered as a 'fictitious' macropore space because it includes real voids as well as the bond volume.

In a general situation the bond mass may increase or decrease as a result of precipitation or dissolution of minerals. Only the solid volume of minerals included in the clay matrix is considered fixed. Therefore $V_{\mathrm{sM}}$ is adopted as the reference volume to define void ratios, as follows.

Void ratio of macropores

$e_{\mathrm{v}}=\frac{V_{\mathrm{v}}}{V_{\mathrm{sM}}}$

Void ratio of bonds

$e_{\mathrm{b}}=\frac{V_{\mathrm{b}}}{V_{\mathrm{sM}}}$

Void ratio of micropores

$e_{\mathrm{m}}=\frac{V_{\mathrm{m}}}{V_{\mathrm{sM}}}$

Void ratio of pores between clay aggregates

$e_{\mathrm{M}}^{*}=\frac{V_{\mathrm{M}}^{*}}{V_{\mathrm{sM}}}=\frac{V_{\mathrm{v}}+V_{\mathrm{b}}}{V_{\mathrm{sM}}}$

First, volumetric strain relationships will be first written; then the results will be generalised to triaxial conditions.

A global (externally observed) volumetric strain will have two components: a change in the topological configuration of the aggregates, and the volume change of the aggregates themselves. The first component introduces the following volumetric strain.

$$
\varepsilon_{\mathrm{vol}}^{\mathrm{M}}=-\frac{\Delta V_{\mathrm{M}}^{*}}{V}=-\frac{\Delta V_{\mathrm{v}}}{V}-\frac{\Delta V_{\mathrm{b}}}{V}
$$

Note that a volumetric strain $\varepsilon_{\mathrm{vol}}^{\mathrm{M}}$ (in compression, for instance) implies a reduction in pore space and a reduction of bond volume. The asterisk $(*)$ is dropped in the remaining paragraphs to simplify the notation.

The second component, the volumetric strain of micropores, is written

$$
\varepsilon_{\mathrm{vol}}^{\mathrm{m}}=-\frac{\Delta V_{\mathrm{m}}}{V}
$$

The volumetric strain of bonding material is defined as

$$
\varepsilon_{\mathrm{vol}}^{\mathrm{b}}=-\frac{\Delta V_{\mathrm{b}}}{V_{\mathrm{b}}}
$$

The straining of bonds is defined locally. The equivalent strain for the representative volume $V$ will be

$$
-\frac{\Delta V_{\mathrm{b}}}{V}=-\frac{\Delta V_{\mathrm{b}}}{V_{\mathrm{b}}} \frac{V_{\mathrm{b}}}{V}=\varepsilon_{\mathrm{vol}}^{\mathrm{b}} C_{\mathrm{b}}
$$

where $C_{\mathrm{b}}$ is the volume concentration of bonding material. 
From equations (4) and (5), the volumetric strain associated with the change in position of aggregates will be

$$
\varepsilon_{\mathrm{vol}}^{\mathrm{M}}=\varepsilon_{\mathrm{vol}}^{\mathrm{V}}+C_{\mathrm{b}} \varepsilon_{\mathrm{vol}}^{\mathrm{b}}
$$

Finally, the measurable 'external' volumetric strain, $\varepsilon_{\mathrm{vol}}^{\mathrm{ext}}$, will be obtained by adding equation (6) and the micro-component.

$$
\begin{aligned}
\varepsilon_{\mathrm{vol}}^{\mathrm{ext}} & =\frac{\Delta V_{\mathrm{v}}+\Delta V_{\mathrm{b}}+\Delta V_{\mathrm{m}}}{V} \\
& =\varepsilon_{\mathrm{vol}}^{\mathrm{V}}+C_{\mathrm{b}} \varepsilon_{\mathrm{vol}}^{\mathrm{b}}+\varepsilon_{\mathrm{vol}}^{\mathrm{m}} \\
& =\varepsilon_{\mathrm{vol}}^{\mathrm{M}}+\varepsilon_{\mathrm{vol}}^{\mathrm{m}}
\end{aligned}
$$

If triaxial conditions are considered the deviatoric strain states are written as

$$
\varepsilon_{\mathrm{q}}^{\mathrm{ext}}=\varepsilon_{\mathrm{q}}^{\mathrm{V}}+C_{\mathrm{b}} \varepsilon_{\mathrm{q}}^{\mathrm{b}}=\varepsilon_{\mathrm{q}}^{\mathrm{M}}
$$

Note that in terms of deviatoric strain the basic model for a non-expansive soft rock is recovered.

\section{Constitutive model: matrix behaviour}

The matrix reacts to changes in stresses $\left(\sigma^{\mathrm{M}}\right)$ and to suction changes. For expansive materials, an explicit consideration of the two structural levels defined for the matrix (micro and macro) was found convenient to describe the features of expansive soil behaviour. A qualitative framework for the model was first described by Gens \& Alonso (1992). The model was later formulated in more detail in Alonso et al. (1999). Within the context of unsaturated soil mechanics, the matrix stress should more properly be defined as a 'net' matrix stress (the excess of total stress over air pressure). 'Matrix stress' will be the term used here for simplicity.

A brief description of the volumetric part of the model is given here. As clay expansion is interpreted as a local hydration phenomenon in which clay aggregates 'capture' the water available in macropores, it is reasonable to assume that, away from equilibrium, two different suction values exist in the soil: a microstructural suction, $s^{\text {micro }}$, prevailing inside the aggregates, and a macrostructural suction existing in macropores. The microstructural behaviour is assumed to be volumetric and non-linear elastic. Mean stress and $s^{\text {micro }}$ control their volumetric response. It is accepted that the mean stress in the aggregates is in equilibrium with the externally applied mean stress on the matrix, $p^{\mathrm{M}}$. Suction in macropores, $s^{\text {macro }}$, will not be necessarily in equilibrium with $s^{\text {micro }}$. Local suction gradients will result in local fluid transfer. However, in the applications presented later, equilibrium will be assumed, and only the drained response of the material will be discussed $\left(s^{\text {macro }}=s^{\text {micro }}=s\right)$

As clay aggregates are supposed to remain saturated, in view of the very small spacing between clay platelets, the effective stress defined by the sum $\left(p^{\mathrm{M}}+s^{\text {micro }}\right)$ holds, and a simple constitutive law may be assumed for the volume change of aggregates.

$$
\mathrm{d} \varepsilon_{\mathrm{vol}}^{\mathrm{m}}=\frac{\kappa_{\mathrm{m}}}{1+e_{\mathrm{m}}} \frac{d\left(p^{\mathrm{M}}+s\right)}{p^{\mathrm{M}}+s}=\frac{\mathrm{d}\left(p^{\mathrm{M}}+s\right)}{K_{\mathrm{m}}}
$$

where $\kappa_{\mathrm{m}}$ is a (constant) compressibility coefficient and $K_{\mathrm{m}}$ is the bulk modulus of clay aggregates.

Macrostructural behaviour (defined as the rearrangement of the clay aggregates) includes the competition of two mechanisms: the response of aggregates to load and suction, as it is considered in a non-expansive material; and the response induced by swelling and shrinkage of the aggre- gates. The first mechanism is modelled through the Barcelona Basic Model (Alonso et al., 1990). The second mechanism is introduced by means of an additional component of volumetric plastic strain that depends on the volumetric change experienced by the microstructure and the distance of the current stress state to the collapse yield loci. The onset of this coupled plastic strain is defined by two additional yield loci: the SD (suction decrease) yield surface, which marks the development of irreversible swelling strains; and the SI (suction increase) surface, which defines the development of irreversible shrinkage.

The elastic response of the arrangement of aggregates (macro) is defined by an expression similar to equation (9), but now the single effective stress principle does not hold, and two separate contributions associated with the matrix stress and the (macro) suction lead to the elastic strain.

$$
\begin{aligned}
\mathrm{d} \varepsilon_{\mathrm{vol}}^{\mathrm{M}^{\mathrm{e}}} & =\frac{\kappa}{1+e_{\mathrm{M}}^{*}} \frac{\mathrm{d} p^{\mathrm{M}}}{p^{\mathrm{M}}}+\frac{\kappa_{\mathrm{s}}}{1+e_{\mathrm{M}}^{*}} \frac{\mathrm{d} s}{\left(s+p_{\mathrm{atm}}\right)} \\
& =\frac{\mathrm{d} p^{\mathrm{M}}}{K_{\mathrm{M}}}+\frac{\mathrm{d} s}{K_{\mathrm{s}}}
\end{aligned}
$$

where $\kappa$ and $\kappa_{\mathrm{s}}$ are the elastic macro-stiffness parameters for changes in mean matrix stress and in macro-suction respectively; $K_{\mathrm{M}}$ and $K_{\mathrm{s}}$ are the bulk elastic moduli of the clay aggregate arrangement against changes in matrix stress and (macro) suction; and $p_{\text {atm }}$ indicates the atmospheric pressure.

A representation of yielding states of the model (for isotropic stress states) is given in Fig. 8 in a plane defined by the mean matrix stress $\left(p^{\mathrm{M}}\right)$ and the suction $s$.

When SI is activated, an additional irreversible strain component equal to the volumetric microstrain $\mathrm{d} \varepsilon_{\mathrm{vol}}^{\text {micro }}$ multiplied by an interaction function $f_{\mathrm{I}}=f_{\mathrm{I} 0}+f_{\mathrm{I} 1} \times$ $\left(p^{\mathrm{M}} / p_{0}^{\mathrm{M}}\right)^{n_{\mathrm{I}}}$ is added to the volumetric matrix strain. When SD is activated, the additional plastic strain component reads $\mathrm{d} \varepsilon_{\mathrm{vol}}^{\mathrm{m}}\left[f_{\mathrm{D} 0}+f_{\mathrm{D} 1}\left(1-p^{\mathrm{M}} / p_{0}^{\mathrm{M}}\right)^{n_{\mathrm{D}}}\right]$, where $p_{0}^{\mathrm{M}}$ represents the yield point on the LC surface at the suction under consideration. Therefore the plastic straining associated with basic (elastic) mineral expansion or contraction is controlled by the current overconsolidation ratio. Note also that $p_{0}^{\mathrm{M}}$ is also a measure of the matrix density. Expressions for the interaction functions $f_{11}$ and $f_{\mathrm{D} 1}$ are given in Alonso et al. (1999). The remaining symbols $\left(f_{\mathrm{I} 0}, n_{\mathrm{I}}, f_{\mathrm{D} 0}, n_{\mathrm{D}}\right)$ are scalar material parameters.

Irreversible plastic straining induced by suction changes modifies the yield stress, $p_{0}^{\mathrm{M}}$. This link helps to model the common observation that swelling strains decrease with in-

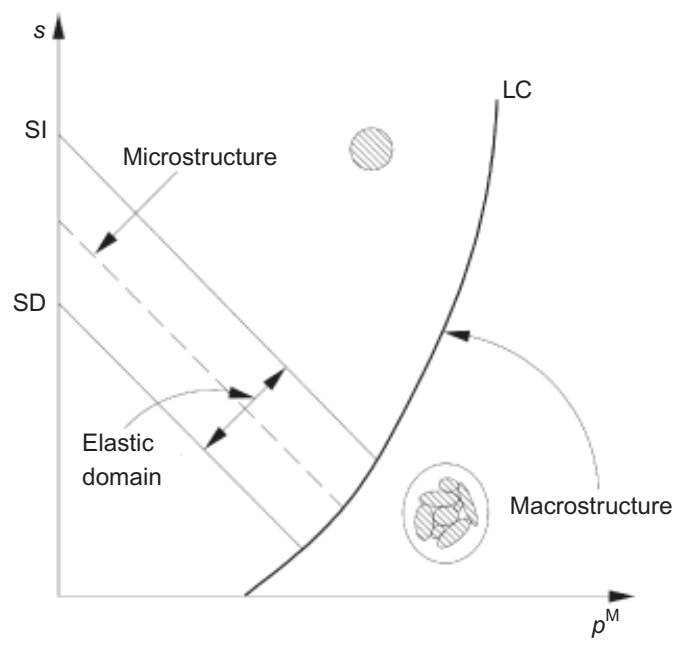

Fig. 8. Elastic zone and yield loci for matrix expansive model (volumetric behaviour) 
creasing confining stress. The formulation of the plastic straining associated with suction changes in terms of two yield limits, SI and SD, helps to reproduce the evolving deformation of clays when several wetting-drying cycles are applied.

\section{Constitutive model: bond behaviour}

Selecting an appropriate constitutive model for the bonding is not an easy task. Its effect on the overall behaviour does not depend only on the properties of the bond material itself or on bond concentration. Probably as important is the three-dimensional geometry of the bonding network and its links with other mineral constituents, namely the clay matrix. It may be expected that, for high bond concentrations, the nature of the bond material will dominate the bond constitutive behaviour. For low to moderate concentrations, which is the case for hard and cemented clay formations, the nature of the bond material has probably a more limited effect. Test results discussed before suggest that bonding introduces a stiff response before yielding, and that it also provides a distinct brittleness. The interpretation of test results suggests also that bonds may fail in compression, in shear or in extension. However, bonding cannot be directly tested, and its properties can only be inferred from global material behaviour. The idea favoured here is that bonding becomes damaged when it is subjected to a given amount of strain energy, irrespective of the stress path applied. This hypothesis is also consistent with the idea that bonding is established once the matrix is stressed. Bond strain energy takes, as a reference zero state, the initial stress of the investigated stress path.

Bond behaviour is modelled through isotropic damage theory. A linear elastic response is assumed for the bond in an undamaged state. Under triaxial conditions, the stressstrain relationship is simply

$$
\begin{aligned}
& p^{\mathrm{b}}=K_{\mathrm{b} 0} \varepsilon_{\mathrm{vol}}^{\mathrm{b}} \\
& q^{\mathrm{b}}=G_{\mathrm{b} 0} \varepsilon_{\mathrm{q}}^{\mathrm{b}}
\end{aligned}
$$

where $K_{\mathrm{b} 0}$ and $G_{\mathrm{b} 0}$ are the bulk and shear moduli of the bond in an intact state.

The isotropic damage is introduced by means of the following simple form.

$$
\begin{aligned}
p^{\mathrm{b}} & =(1-D) K_{\mathrm{b} 0} \varepsilon_{\mathrm{vol}}^{\mathrm{b}}=K_{\mathrm{b}} \varepsilon_{\mathrm{vol}}^{\mathrm{b}} \\
q^{\mathrm{b}} & =(1-D) G_{\mathrm{b} 0} \varepsilon_{\mathrm{q}}^{\mathrm{b}}=G_{\mathrm{b}} \varepsilon_{\mathrm{q}}^{\mathrm{b}}
\end{aligned}
$$

$D$ is the scalar damage parameter, which represents the damaged area of bonds over the total area of bond. It takes the value 0 when the material is intact, and 1 when all the bond is damaged. $K_{\mathrm{b}}=(1-D) K_{\mathrm{b} 0}$ and $G_{\mathrm{b}}=(1-D) G_{\mathrm{b} 0}$ are the bulk and shear modulus of the bond in the current damaged state.

As proposed by Carol et al. (2001), an alternative damage variable is used,

$$
L=\ln \left(\frac{1}{1-D}\right)
$$

which varies from 0 to $\infty$

Using the logarithmic damage variable, the bond bulk and shear moduli are written as

$$
\begin{aligned}
& K_{\mathrm{b}}=\mathrm{e}^{-L} K_{\mathrm{b} 0} \\
& G_{\mathrm{b}}=\mathrm{e}^{-L} G_{\mathrm{b} 0}
\end{aligned}
$$

The evolution of $L$ is required to define the degradation of bond stiffness totally, and to determine the bond behaviour.

Carol et al. (2001) proposed that damage and subsequent changes of $L$ should be linked to the increments of energy stored in the bonds per unit of volume. This energy is defined as the elastic secant energy that would be recovered upon unloading $\left(u_{\mathrm{b}}=\frac{1}{2}\left(p^{\mathrm{b}} \varepsilon_{\mathrm{vol}}^{\mathrm{b}}+q^{\mathrm{b}} \varepsilon_{\mathrm{q}}^{\mathrm{b}}\right)\right)$

With this formulation, the current bond damage locus is defined by a threshold $\left(r_{0}\right)$ of the secant elastic energy that can be represented by an ellipse in $\left(p^{\mathrm{b}}, q^{\mathrm{b}}\right)$ space. Inside this ellipse, the bond stiffness remains constant. When changes in the tensional state of the bond lead the secant elastic energy to reach the threshold, damage takes place ( $L$ increases) and stiffness reduces. The damage evolution is determined by means of the function suggested by Carol et al. (2001):

$$
r(L)=r_{0} \mathrm{e}^{r_{1} L}=u_{\mathrm{b}}
$$

where $r_{1}$ determines the damage rate. The consistency condition associated with this energy locus allows the determination of $L$.

\section{Strain partition}

An assumption is now made concerning the form of the bond strain $\varepsilon^{\mathrm{b}}$.

$$
\begin{aligned}
& \varepsilon_{\mathrm{vol}}^{\mathrm{b}}=\chi \varepsilon_{\mathrm{vol}}^{\mathrm{v}} \\
& \varepsilon_{\mathrm{q}}^{\mathrm{b}}=\chi \varepsilon_{\mathrm{q}}^{\mathrm{v}}
\end{aligned}
$$

where $\chi\left(\chi_{0}, L\right)$ is assumed to depend on an initial reference value $\chi_{0}$, and on the logarithmic damage variable $L$. Equations (16) explain that in a highly damaged material $(\chi$ is small) the local bond deformation will be small when the macrovoids are deformed (Fig. 5(d) illustrates this idea). Conversely, the local bond strain will increase when damage is reduced, because the bond stiffness is high in comparative terms.

Therefore, from equations (16), (7) and (8),

$$
\begin{aligned}
& \varepsilon_{\mathrm{vol}}^{\mathrm{b}}=\frac{\chi}{1+\chi C_{\mathrm{b}}} \varepsilon_{\mathrm{vol}}^{\mathrm{M}} \\
& \varepsilon_{\mathrm{q}}^{\mathrm{b}}=\frac{\chi}{1+\chi C_{\mathrm{b}}} \varepsilon_{\mathrm{q}}^{\mathrm{M}}
\end{aligned}
$$

The following relationship is adopted for $\chi$ :

$$
\chi=\chi_{0} \mathrm{e}^{-L / 2}
$$

where parameter $\chi_{0}$ provides the strain partition before any bond damage has occurred. This is a constitutive parameterthe bonding deformation parameter for the undamaged state.

\section{Stress partition: conjugate variables}

Two stress components perform work: a stress associated with the matrix aggregates $\left(p^{\mathrm{M}}\right.$ and $\left.q^{\mathrm{M}}\right)$, and a stress resisted by the bonds $\left(p^{\mathrm{b}}\right.$ and $\left.q^{\mathrm{b}}\right) . p^{\mathrm{M}}$ and $q^{\mathrm{M}}$ deform the clay aggregates and modify its relative position, creating additional straining. Therefore the matrix stress acts on the external strain $\varepsilon^{\text {ext }}$, the only one being measured. The bond stress performs work when the bond deforms $\left(C_{b} \varepsilon^{b}\right)$.

In order to derive an expression for the external stress $\sigma^{\text {ext }}$ in terms of the two defined stress components, the principle of virtual work is applied as follows.

$$
\begin{aligned}
p^{\text {ext }} \mathrm{d} \varepsilon_{\mathrm{vol}}^{\text {ext }}+q^{\text {ext }} \mathrm{d} \varepsilon_{\mathrm{q}}^{\text {ext }}= & p^{\mathrm{M}} \mathrm{d} \varepsilon_{\mathrm{vol}}^{\text {ext }}+q^{\mathrm{M}} \mathrm{d} \varepsilon_{\mathrm{q}}^{\text {ext }} \\
& +p^{\mathrm{b}} C_{\mathrm{b}} \mathrm{d} \varepsilon_{\mathrm{vol}}^{\mathrm{b}}+q^{\mathrm{b}} C_{\mathrm{b}} \mathrm{d} \varepsilon_{\mathrm{q}}^{\mathrm{b}}
\end{aligned}
$$

Equation (19), valid for any external change in strain, provides a procedure to find the external stress associated 
with any change in external strain, as illustrated in the following simplified cases.

Infinitely rigid clay aggregates and no damage The soil does not exhibit any expansion or shrinkage phenomena. The material is now a cemented granular soil. The bond strain, in view of equations (7), (8) and (17) will be

$$
\begin{gathered}
\varepsilon_{\mathrm{vol}}^{\mathrm{b}}=\frac{\chi}{1+\chi C_{\mathrm{b}}} \varepsilon_{\mathrm{vol}}^{\mathrm{ext}} \\
\varepsilon_{\mathrm{q}}^{\mathrm{b}}=\frac{\chi}{1+\chi C_{\mathrm{b}}} \varepsilon_{\mathrm{q}}^{\mathrm{ext}}
\end{gathered}
$$

Substituting these values in equation (19) and assuming no damage ( $\chi$ constant),

$$
\begin{aligned}
p^{\mathrm{ext}} \Delta \varepsilon_{\mathrm{vol}}^{\mathrm{ext}}+q^{\mathrm{ext}} \Delta \varepsilon_{\mathrm{q}}^{\mathrm{ext}}= & p^{\mathrm{M}} \Delta \varepsilon_{\mathrm{vol}}^{\mathrm{ext}}+q^{\mathrm{M}} \Delta \varepsilon_{\mathrm{q}}^{\mathrm{ext}} \\
& +\frac{C_{\mathrm{b}} \chi}{1+\chi C_{\mathrm{b}}}\left(p^{\mathrm{b}} \Delta \varepsilon_{\mathrm{vol}}^{\mathrm{ext}}+q^{\mathrm{b}} \Delta \varepsilon_{\mathrm{q}}^{\mathrm{ext}}\right)
\end{aligned}
$$

and as equation (21) is valid for any $\Delta \varepsilon^{\text {ext }}$,

$$
\begin{aligned}
& p^{\mathrm{ext}}=p^{\mathrm{M}}+\frac{C_{\mathrm{b}} \chi}{1+C_{\mathrm{b}} \chi} p^{\mathrm{b}} \\
& q^{\mathrm{ext}}=q^{\mathrm{M}}+\frac{C_{\mathrm{b}} \chi}{1+C_{\mathrm{b}} \chi} q^{\mathrm{b}}
\end{aligned}
$$

For a given $C_{\mathrm{b}}, \chi$ determines the redistribution of external stress among the bond and the matrix. When damage occurs and $\chi$ decreases, stress is progressively transferred from bond to matrix. When a fully destructured state is reached, the bond has lost its stiffness and strength, and the external stress is fully applied to the clay matrix. When the bond concentration vanishes $\left(C_{\mathrm{b}}=0\right)$ the external stress is also fully applied to the clay matrix.

Elastic behaviour of matrix and no damage (at constant suction) The bond stress is given by

$$
\begin{aligned}
\Delta p^{\mathrm{b}} & =K_{\mathrm{b}} \Delta \varepsilon_{\mathrm{vol}}^{\mathrm{b}} \\
& =K_{\mathrm{b}} \frac{\chi}{1+C_{\mathrm{b} \chi}} \Delta \varepsilon_{\mathrm{vol}}^{\mathrm{M}} \\
& =\frac{\chi}{1+C_{\mathrm{b}} \chi} \frac{K_{\mathrm{b}}}{K_{\mathrm{M}}} \Delta p^{\mathrm{M}} \\
\Delta q^{\mathrm{b}} & =G_{\mathrm{b}} \Delta \varepsilon_{\mathrm{q}}^{\mathrm{b}} \\
& =G_{\mathrm{b}} \frac{\chi}{1+C_{\mathrm{b}}} \Delta \varepsilon_{\mathrm{q}}^{\mathrm{M}} \\
& =\frac{\chi}{1+C_{\mathrm{b}} \chi} \frac{G_{\mathrm{b}}}{G_{\mathrm{M}}} \Delta q^{\mathrm{M}}
\end{aligned}
$$

where equations (9) and (11) have been used.

If the matrix constitutive law is now invoked,

$$
\begin{aligned}
\Delta p^{\mathrm{M}} & =K_{\mathrm{M}} \Delta \varepsilon_{\mathrm{vol}}^{\mathrm{M}} \\
& =K_{\mathrm{M}}\left(\Delta \varepsilon_{\mathrm{vol}}^{\mathrm{ext}}-\Delta \varepsilon_{\mathrm{vol}}^{\mathrm{m}}\right) \\
\Delta q^{\mathrm{M}} & =G_{\mathrm{M}} \Delta \varepsilon_{\mathrm{q}}^{\mathrm{M}}=G_{\mathrm{M}} \Delta \varepsilon_{\mathrm{q}}^{\mathrm{ext}}
\end{aligned}
$$

where the micro volumetric strain is given by

$$
\Delta \varepsilon_{\mathrm{vol}}^{\mathrm{m}}=\frac{\Delta p^{\mathrm{M}}}{K_{\mathrm{m}}}
$$

Then

$$
\begin{aligned}
\Delta p^{\mathrm{M}} & =\left(\frac{1}{K_{\mathrm{M}}}+\frac{1}{K_{\mathrm{m}}}\right)^{-1} \Delta \varepsilon_{\mathrm{vol}}^{\mathrm{ext}}=K_{\mathrm{Mext}} \Delta \varepsilon_{\mathrm{vol}}^{\mathrm{ext}} \\
\Delta q^{\mathrm{M}} & =G_{\mathrm{M}} \Delta \varepsilon_{\mathrm{q}}^{\mathrm{ext}}
\end{aligned}
$$

where $K_{\text {Mext }}$ is the average bulk modulus of the clay matrix. Therefore

$$
\begin{aligned}
\Delta p^{\mathrm{b}} & =\left(\frac{\chi}{1+C_{\mathrm{b} \chi}}\right) \frac{K_{\mathrm{b}}}{K_{\mathrm{M}}} K_{\mathrm{Mext}} \Delta \varepsilon_{\mathrm{vol}}^{\mathrm{ext}}=K_{\mathrm{bext}} \Delta \varepsilon_{\mathrm{vol}}^{\mathrm{ext}} \\
\Delta q^{\mathrm{b}} & =\left(\frac{\chi}{1+C_{\mathrm{b} \chi}}\right) G_{\mathrm{b}} \Delta \varepsilon_{\mathrm{q}}^{\mathrm{ext}}
\end{aligned}
$$

where a bulk modulus for the bond stress, $K_{\text {bext }}$, has been defined in terms of the external volumetric strain.

The principle of virtual work (equation (19)), valid for any external strain, is now written as

$$
\begin{aligned}
& p^{\text {ext }} \Delta \varepsilon_{\mathrm{vol}}^{\mathrm{ext}}=p^{\mathrm{M}} \Delta \varepsilon_{\mathrm{vol}}^{\mathrm{ext}}+C_{\mathrm{b}} p^{\mathrm{b}} \Delta \varepsilon_{\mathrm{vol}}^{\mathrm{b}} \\
& q^{\text {ext }} \Delta \varepsilon_{\mathrm{q}}^{\mathrm{ext}}=q^{\mathrm{M}} \Delta \varepsilon_{\mathrm{q}}^{\mathrm{ext}}+C_{\mathrm{b}} p^{\mathrm{b}} \Delta \varepsilon_{\mathrm{q}}^{\mathrm{b}}
\end{aligned}
$$

where

$$
\begin{aligned}
& \Delta \varepsilon_{\mathrm{vol}}^{\mathrm{b}}=\frac{\chi}{1+C_{\mathrm{b} \chi}} \Delta \varepsilon_{\mathrm{vol}}^{\mathrm{M}}=\frac{\chi}{1+C_{\mathrm{b} \chi}} \frac{K_{\mathrm{Mext}}}{K_{\mathrm{M}}} \Delta \varepsilon_{\mathrm{vol}}^{\mathrm{ext}} \\
& \Delta \varepsilon_{\mathrm{q}}^{\mathrm{b}}=\frac{\chi}{1+C_{\mathrm{b} \chi} \chi} \Delta \varepsilon_{\mathrm{q}}^{\mathrm{M}}=\frac{\chi}{1+C_{\mathrm{b}} \chi} \Delta \varepsilon_{\mathrm{q}}^{\mathrm{ext}}
\end{aligned}
$$

Therefore, from equations (27) and (28),

$$
\begin{aligned}
& p^{\mathrm{ext}}=p^{\mathrm{M}}+p^{\mathrm{b}} \frac{\chi}{1+C_{\mathrm{b}} \chi} \frac{K_{\mathrm{Mext}}}{K_{\mathrm{M}}} \\
& q^{\mathrm{ext}}=q^{\mathrm{M}}+q^{\mathrm{b}} \frac{\chi}{1+C_{\mathrm{b}} \chi}
\end{aligned}
$$

These equations provide the expression for the external stresses in terms of bond and matrix stresses. In a general case, the stress partition cannot be expressed in a closed form. The constitutive equation has to be integrated numerically. Again, an increment of external strain is applied to the model. The first step is to find the macro and micro strain components $\left(\Delta \varepsilon^{\mathrm{ext}}=\Delta \boldsymbol{\varepsilon}^{\mathrm{M}}+\Delta \boldsymbol{\varepsilon}^{\mathrm{m}}\right)$. As each strain component is associated with the matrix stress, the expansive elasto-plastic model provides the changes in $\left(p^{\mathrm{M}}, q^{\mathrm{M}}\right)$ stress (and allows computation of the current macro stress $\left(p^{\mathrm{M}}\right.$, $\left.q^{\mathrm{M}}\right)$ ). The incremental bond strain is then calculated in terms of $\Delta \varepsilon^{\mathrm{m}}$ and the current value of $\chi$ and bond concentration $\left(C_{\mathrm{b}}\right)$ through equation (20). Integrating the damage model, the incremental bond stress $\left(\Delta p^{\mathrm{b}}, \Delta q^{\mathrm{b}}\right)$ is calculated and $\left(p^{\mathrm{b}}, q^{\mathrm{b}}\right)$ is updated. Finally, a direct use of the principle of virtual work equation provides the value of $\left(p^{\text {ext }}, q^{\text {ext }}\right)$.

\section{FEATURES OF THE MODEL THROUGH SIMULATED TESTS}

A few simple tests have been run to illustrate the model capabilities in a parametric study. Synthetic oedometric and triaxial tests have been simulated on two hypothetical nonexpansive bonded clays. A third case deals with the degradation induced by suction changes.

\section{Oedometric behaviour: effect of initial damage state ( $\left.r_{0}\right)$} and damage rate $\left(r_{1}\right)$

A material defined with the parameters presented in Table 1 (column 1) has been chosen to illustrate the oedometric response of a bonded soil. The results, plotted in Figs 9 and 10 , illustrate the effect of varying the initial damage state 
Table 1. Material parameters for cases shown

\begin{tabular}{|c|c|c|c|c|c|c|c|}
\hline \multirow[t]{3}{*}{ Symbol } & \multirow[t]{3}{*}{ Definition of parameter } & \multicolumn{5}{|c|}{ Value } & \multirow[t]{3}{*}{ Units } \\
\hline & & 1 & 2 & 3 & 4 & 5 & \\
\hline & & Oedometer & Triaxial & Suction cycles & La Biche shale & Todi clay & \\
\hline$v_{\mathrm{M}}$ & $\begin{array}{l}\text { Matrix Poisson's ratio } \\
\text { Expansive matrix }\end{array}$ & $0 \cdot 3$ & $0 \cdot 3$ & $0 \cdot 3$ & $0 \cdot 3$ & $0 \cdot 3$ & - \\
\hline$\kappa$ & Elastic macro stiffness parameter for changes in net mean stress & $0 \cdot 05$ & 0.005 & 0.01 & 0.01 & 0.008 & - \\
\hline$\kappa_{\mathrm{s}}$ & Elastic macro stiffness parameter for changes in suction & 0.005 & $0 \cdot 005$ & 0.01 & $0 \cdot 001$ & $0 \cdot 01$ & - \\
\hline$\kappa_{\mathrm{m}}$ & Elastic micro stiffness parameter for changes in effective mean stress & $\begin{array}{l}\text { Non-expansive } \\
\text { matrix }\end{array}$ & $\begin{array}{l}\text { Non-expansive } \\
\text { matrix }\end{array}$ & $\begin{array}{l}\text { Analysed } \\
\text { parameter }\end{array}$ & $0 \cdot 012$ & $0 \cdot 01$ & - \\
\hline$\lambda(0)$ & Macro stiffness parameter for virgin states in saturated conditions & $0 \cdot 25$ & 0.074 & 0.054 & 0.054 & 0.04 & - \\
\hline$r, \beta$ & $\begin{array}{l}\text { Parameters that describe the rate of changes of virgin compressibility } \\
\text { parameter with macro suction }\end{array}$ & $0 \cdot 75,0 \cdot 1$ & $0 \cdot 75,0 \cdot 1$ & $0 \cdot 75,0 \cdot 1$ & $0 \cdot 75,0 \cdot 1$ & $0 \cdot 75,0 \cdot 1$ &,$- \mathrm{MPa}^{-1}$ \\
\hline M & Slope of critical-state line & $0 \cdot 8$ & $1 \cdot 0$ & $1 \cdot 0$ & 0.5 & $1 \cdot 0$ & - \\
\hline$k_{\mathrm{s}}$ & Parameter that controls the increase of cohesion with suction & $0 \cdot 0$ & $0 \cdot 0$ & $0 \cdot 0$ & $0 \cdot 0$ & $0 \cdot 0$ & - \\
\hline$p_{0}^{\mathrm{M}^{*}}$ & Mean yield stress for saturated conditions & $0 \cdot 011$ & $3 \cdot 0$ & $3 \cdot 0$ & $2 \cdot 5$ & $6 \cdot 0$ & $\mathrm{MPa}$ \\
\hline & Reference stress & 0.042 & $0 \cdot 042$ & & $0 \cdot 01$ & $0 \cdot 042$ & $\mathrm{MPa}$ \\
\hline$s_{\mathrm{I}}, s_{\mathrm{D}}$ & Hardening parameters for SI and SD yield surfaces respectively & $\begin{array}{l}\text { Non-expansive } \\
\text { matrix }\end{array}$ & $\begin{array}{l}\text { Non-expansive } \\
\text { matrix }\end{array}$ & $10 \cdot 05,10 \cdot 05$ & $0 \cdot 55,0 \cdot 45$ & $0 \cdot 02,0 \cdot 02$ & $\mathrm{MPa}$ \\
\hline$f_{10}, f_{11}, n_{\mathrm{I}}$ & Parameters micro-macro coupling functions when SI is active & $\begin{array}{l}\text { Non-expansive } \\
\text { matrix }\end{array}$ & $\begin{array}{l}\text { Non-expansive } \\
\text { matrix }\end{array}$ & $0 \cdot 0,1 \cdot 2,1 \cdot 0$ & $0 \cdot 0,1 \cdot 2,1 \cdot 0$ & $0 \cdot 45,3 \cdot 0,1 \cdot 5$ & - \\
\hline$f_{\mathrm{D} 0}, f_{\mathrm{D} 1}, n_{\mathrm{D}}$ & Parameters micro-macro coupling functions when SD is active & $\begin{array}{l}\text { Non-expansive } \\
\text { matrix }\end{array}$ & $\begin{array}{l}\text { Non-expansive } \\
\text { matrix }\end{array}$ & $0 \cdot 5,1 \cdot 2,1 \cdot 0$ & $1 \cdot 0,1 \cdot 2,1 \cdot 0$ & $1 \cdot 0,2 \cdot 5,5 \cdot 5$ & - \\
\hline$C_{\mathrm{b}}$ & $\begin{array}{l}\text { Bond } \\
\text { Bond concentration }\end{array}$ & $0 \cdot 4$ & $\begin{array}{l}\text { Analysed } \\
\text { parameter }\end{array}$ & $0 \cdot 6$ & $0 \cdot 7$ & $0 \cdot 1$ & - \\
\hline$K_{\mathrm{b} 0}$ & Bond undamaged bulk modulus & 10 & 3000 & $100 \cdot 0$ & 130 & 110 & $\mathrm{MPa}$ \\
\hline$G_{\mathrm{b} 0}$ & Bond undamaged shear modulus & $3 \cdot 85$ & 1154 & 38 & 50 & 42 & $\mathrm{MPa}$ \\
\hline$r_{0}$ & Initial elastic energy of bond that defines initial bond damage state & $\begin{array}{l}\text { Analysed } \\
\text { parameter }\end{array}$ & $0 \cdot 1$ & $0 \cdot 001$ & $0 \cdot 02$ & $0 \cdot 001$ & $\mathrm{MPa}$ \\
\hline$r_{1}$ & Bond damage rate & $\begin{array}{l}\text { Analysed } \\
\text { parameter }\end{array}$ & $0 \cdot 05$ & $0 \cdot 05$ & $-0 \cdot 3$ & $0 \cdot 15$ & - \\
\hline$\chi_{0}$ & $\begin{array}{l}\text { Coupling } \\
\text { Bonding deformation parameter for undamaged state }\end{array}$ & $1 \cdot 0$ & $\begin{array}{l}\text { Analysed } \\
\text { parameter }\end{array}$ & $1 \cdot 0$ & $5 \cdot 0$ & $1 \cdot 0$ & - \\
\hline
\end{tabular}


146

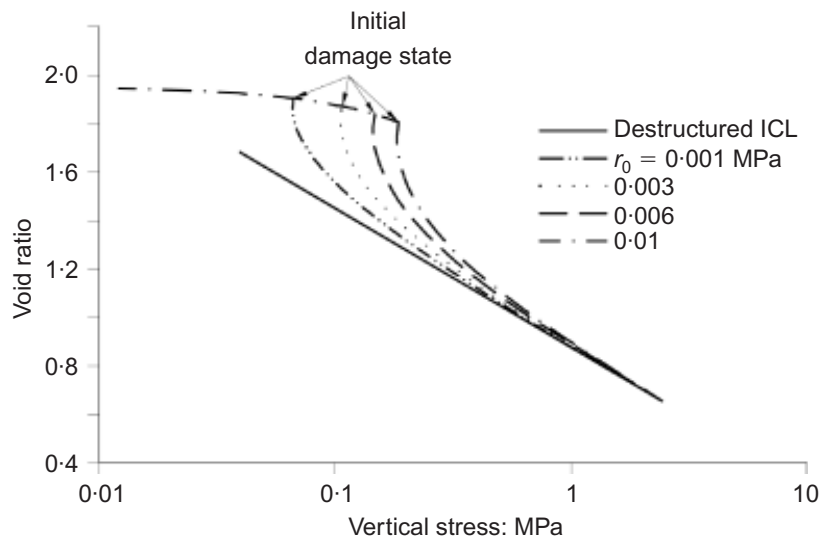

Fig. 9. Set of simulated oedometer tests for a bonded material: effect of initial damage state $r_{0}$

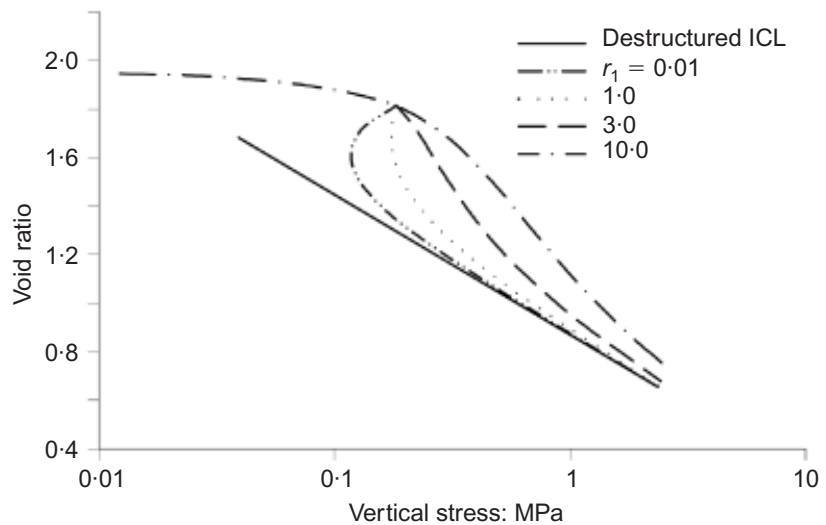

Fig. 10. Set of simulated oedometer tests for a bonded material: effect of damage rate $r_{1}$

$\left(r_{0}\right)$ and damage rate $\left(r_{1}\right)$. For a given bond concentration $C_{\mathrm{b}}$ and a given bonding deformation parameter $\chi_{0}$, the initial stiff response of the material corresponds to the undisturbed state. The slope of the first part of the compression curve is identical for all the simulated tests. The initiation of damage is controlled by the initial size of the bond energy locus $\left(r_{0}\right)$. As load is increased, the induced damage results in a sharp transition towards a softer response (Fig. 9). As strain accumulates, the material evolves toward the matrix behaviour. The reason for this is that, as bonding degrades, the stress is progressively transferred to the matrix. The elastoplastic matrix response (a continuous line in Fig. 9) has been computed with the same parameters of the undisturbed bonded material but with $C_{\mathrm{b}}=0$ imposed.

The evolution of damage is controlled by the rate parameter $r_{1}$ (Fig. 10): the higher $r_{1}$ is, the smoother is the transition from an undisturbed to a damaged state.

Triaxial behaviour: effect of bond deformation parameter $(\chi)$ and bond concentration $\left(C_{\mathrm{b}}\right)$

To illustrate the behaviour under triaxial conditions, a hypothetical soft rock has been defined. Material parameters are given in column 2 of Table 1. Compared with the bonded soil described in the previous section, the higher bond concentration and stiffer bond moduli define a more indurated material. The bond strength is controlled partially by the $r_{0}$ value, because it marks the maximum (secant) strain energy accepted by the bonds before the degradation process is initiated.

The bonding deformation parameter $\chi_{0}$ also controls the initial stiffness and peak strength of the composite material, because it provides the amount of straining arriving at the bonds (see equations (17) and (18)). $\chi_{0}$ is a constitutive variable that defines the effectiveness of the bond to limit the changes in macroporosity when stress is applied. A high value $\left(\chi_{0}=5\right)$ indicates that porosity changes are essentially described by bond deformation. In the opposite extreme $\left(\chi_{0}\right.$ $=0)$, the bond material does not oppose any restriction to the matrix deformation. Isolated bodies of bond material, scattered in a clay matrix, provide a conceptual model for a $\chi_{0}=0$ situation (Fig. $5(\mathrm{~d})$ ).

Figure 11 shows the effect of $\chi_{0}$ on the triaxial stress response $\left(\Delta \sigma_{3}=0 ; \Delta \sigma_{1}>0\right)$ of the composite material. In all cases a concentration $C_{\mathrm{b}}=0.6$ is assumed. When $\chi_{0}=$ 0 , the matrix behaviour is recovered. For any strain, an effective bonding $(\chi>0)$ results in a higher mobilised deviatoric stress. Accumulation of strain destroys the effectiveness of bonds, and the (residual) strength of the material approximates the matrix behaviour.

The effect of bond concentration (when $\chi_{0}=1$ ) is analysed in Fig. 12 for the same material. Bond concentration $C_{\mathrm{b}}$ is assumed to change from $80 \%$ to $0 \%$. The initial stiffness now remains fairly constant, but the peak strengths change substantially with the amount of bonding. The bond degradation law provides a typical strain-softening behaviour. However, in some tests, when the bond concentration is low, the matrix behaviour at large strains provides a slow, ductile gain in strength. This effect could be removed by changing some of the model parameters, but it shows the capabilities of linking two different basic material behaviours (bond and matrix).

Degradation induced by wetting-drying cycles

In the previous examples, no reference to suction was made. Now, the effect of a common situation in exposed

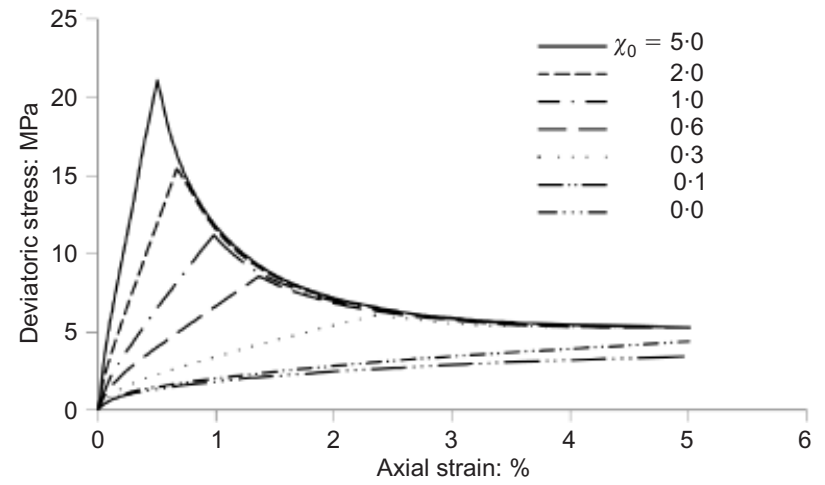

Fig. 11. Set of simulated triaxial tests for a bonded material: effect of initial bonding deformation parameter $\chi_{0}$

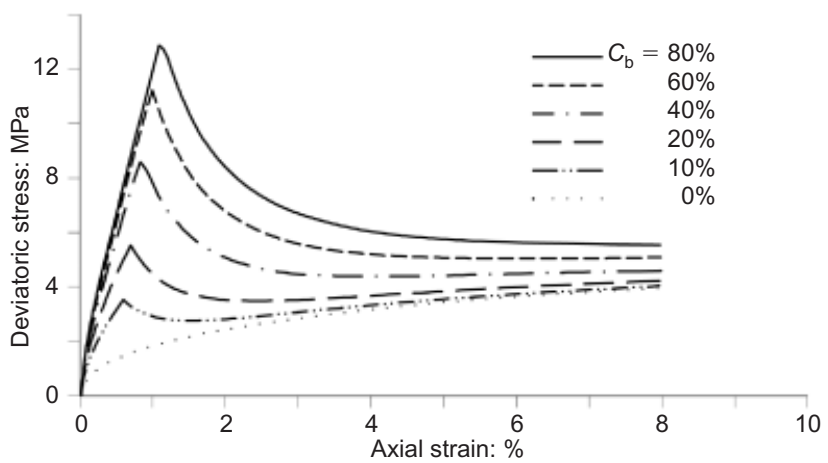

Fig. 12. Set of simulated triaxial tests for a bonded material: effect of bond concentration $C_{\mathrm{b}}$ 
materials, namely the application of weather-induced suction cycles, will be explored. This is believed to be an important ultimate reason for rock degradation.

The matrix now reacts to suction changes and, as irreversible volumetric swelling accumulates, bonding is degraded. Material parameters are given in Table 1 (column 3). The values of the coefficient of the interaction functions lead to an accumulation of plastic expansion as cycles are imposed. The imposed suction cycles are schematically given in Fig. 13 (during cycles, suction ranges from $100 \mathrm{MPa}$ to $0.5 \mathrm{MPa}$ ). Three clay materials are considered, each characterised by a different expansion potential. Aspects controlling the expansion potential are the nature of the clay minerals, the density of the clay matrix, the confining stress, and the specific arrangement or geometry of clay aggregates in the clayey rock. In the model, the nature of the clay minerals dictates the basic microstructural response (equation (9)); the density of the clay matrix is reflected in the position of the LC yield locus (Fig. 8); the effects of the confining stress are included in the non-linear basic law of microstructured response (equation (9)), and they are explicitly introduced in the structure of the interaction macromicro functions $f_{\mathrm{I}}$ or $f_{\mathrm{D}}$. The effectiveness of mineral expansion to induce macrostructural irreversible deformations is also included in $f_{\mathrm{I}}$ and $f_{\mathrm{D}}$.

The expansion potential of the three materials considered

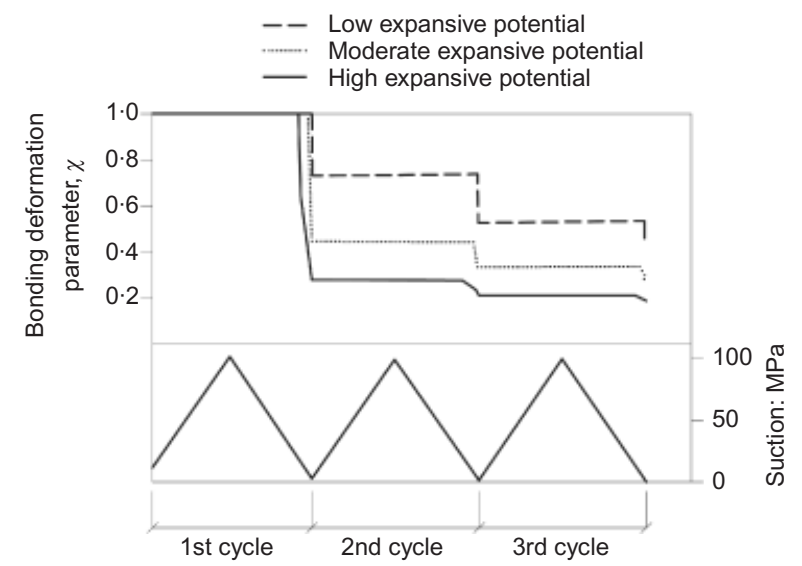

Fig. 13. Applied suction cycles and evolution of deformation parameter $\chi$ has been simply represented by a different elastic stiffness of the microstructure, $\kappa_{\mathrm{m}}=0.001,0.004$ and 0.009 . These three materials are identified as having a low, a moderate, and a high expansive potential respectively. Numerical tests were run under isotropic stress conditions and a confining stress of $0.05 \mathrm{MPa}$. The calculated evolution of the deformation parameter is given in Fig. 13. Degradation in $\chi$ occurs rapidly, once the bond limiting surface is reached. As $\chi$ evolves, the material degrades and the volumetric strains increase, as shown in Fig. 14. The accumulated irreversible volumetric strains during drying-wetting induce bond damage, and the full potential of the clay matrix is progressively released. 'Tests' were stopped when some effective bonding was still available in the three specimens.

\section{MODELLING SOME REPORTED EXPERIMENTS \\ The behaviour of La Biche shale (Wong, 1998)}

The particular triaxial tests reproduced in Fig. 7(b) were selected for the comparison exercise. The triaxial response of the intact rock specimen, under a confining stress of $50 \mathrm{kPa}$, is compared with the triaxial response of the same material once it was subjected to a drying-wetting cycle. No details of the suction reached during drying are given in Wong's paper, but as the specimen was exposed to the atmosphere of the laboratory, a high suction (100 MPa) was applied in the simulation. The subsequent wetting is simulated by reducing suction to a low value $(0.5 \mathrm{MPa})$. Then the damaged specimen was sheared under a $50 \mathrm{kPa}$ confining stress. The stress paths of the two specimens to be compared are given in Fig. 15.

The selection of model parameters was facilitated by some additional data given in Wong's paper. It was reported that he measured the free swelling strain of the wetted specimen at around $15 \%$. For the simulation as performed, the calculated shrinkage and swelling strains are given in Fig. 16(a). A final swelling strain close to $13 \%$ was obtained in the model. The set of material parameters selected for La Biche shale are given in Table 1 (column 4).

The experimental and calculated triaxial responses of the two specimens are compared in Fig. 17. The model captures well the extreme degradation experienced by this material during the swelling cycle. The deviatoric response is reasonably well reproduced. The volumetric response shows the correct trends: the undisturbed specimen dilates strongly

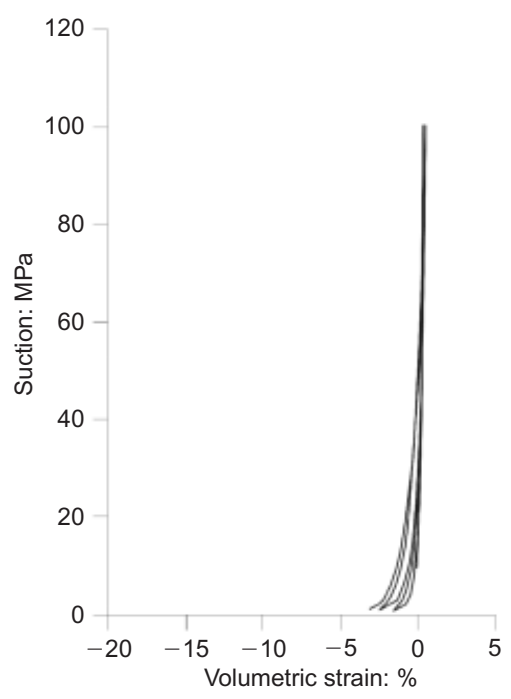

(a)

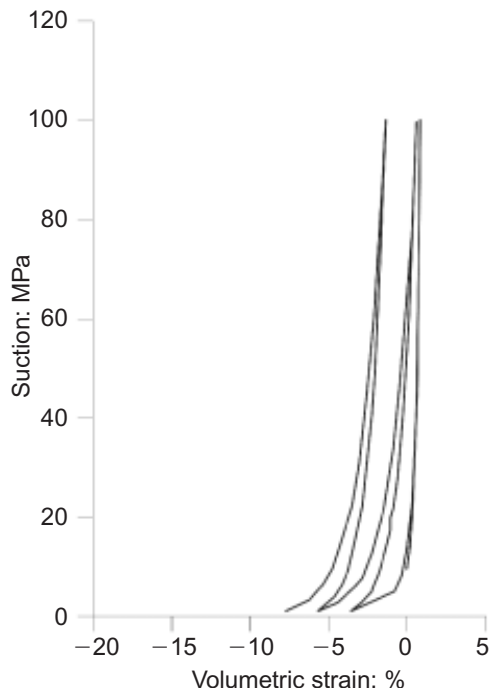

(b)

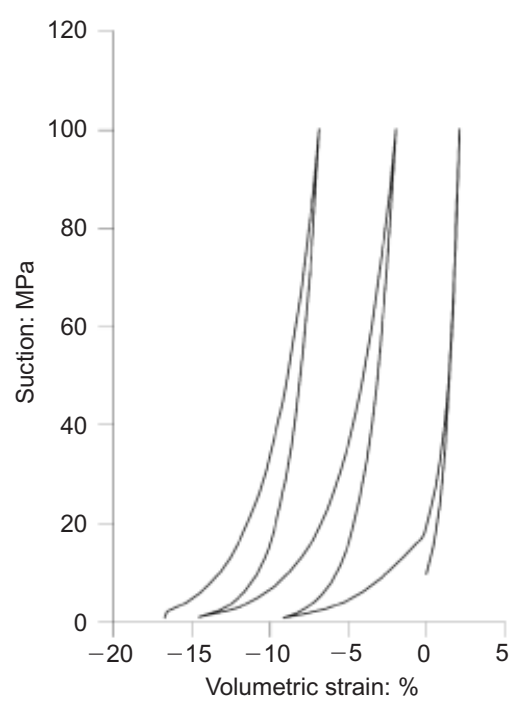

(c)

Fig. 14. Calculated expansion of three simulated tests under suction cycles: (a) low, (b) moderate and (c) high expansion potential of clay matrix 


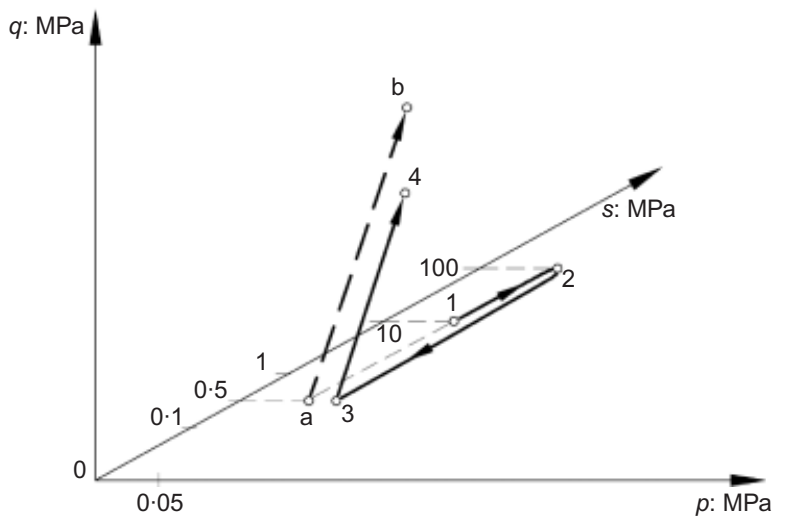

Fig. 15. Stress paths of $\mathbf{L a}$ Biche shale tests: $\mathbf{a}-\mathbf{b}$, intact specimen; 1-2-3-4, specimen preconditioned by a dryingwetting cycle

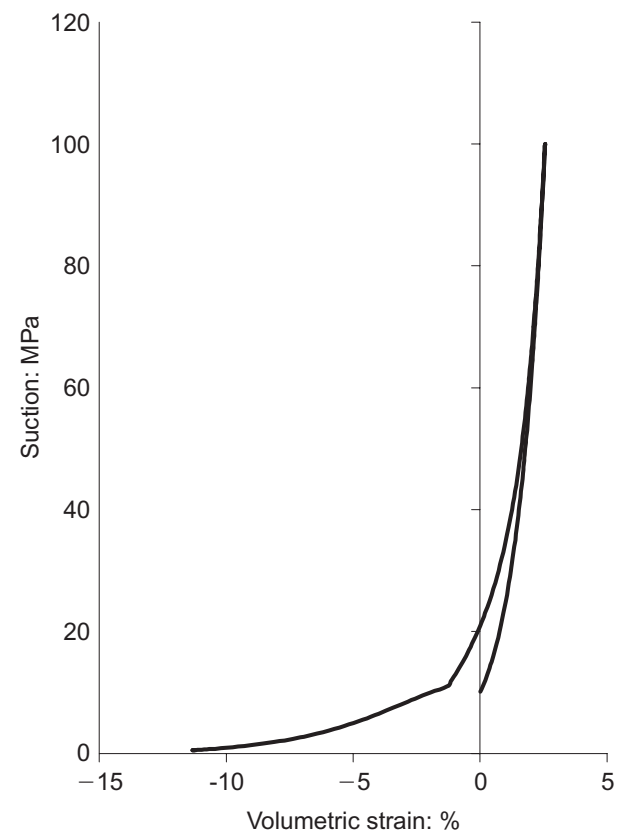

(a)

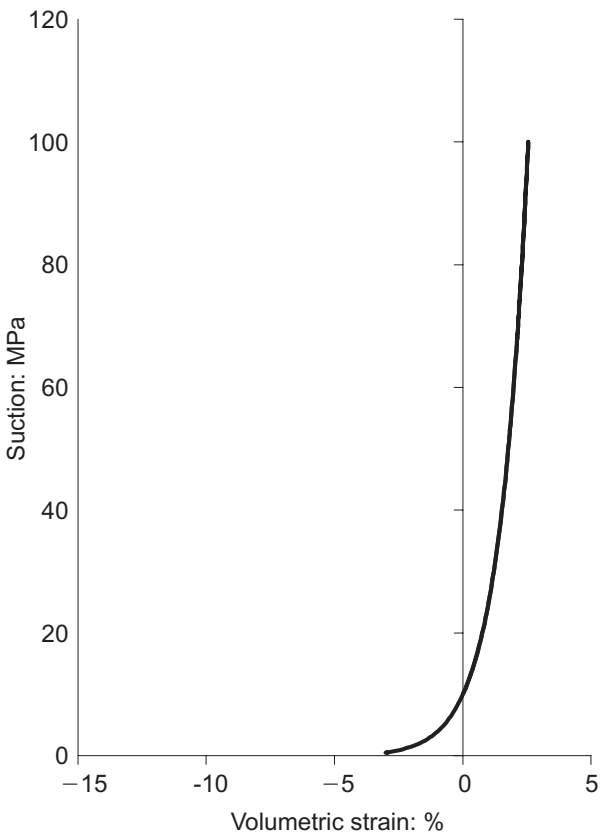

(b)

Fig. 16. La Biche shale model. Calculated swelling strains during the drying-wetting cycle: (a) expansive matrix; (b) non-expansive matrix after peak strength. However, the expanded material shows a strong compressive behaviour during shear, probably explained by the extreme degradation of the shale after several days of unconfined soaking, which is not well reproduced by the model.

Further insight into the developed model is obtained by comparing the performance of a swelling and a non-swelling clay matrix. If material parameters are maintained, except for the microstructural volumetric swelling strains (equation (9)), which are now removed, the model response is as shown in Figs 16(b) and 17(b). Final wetting strains are now much smaller, and they scarcely damage the bond component of the model at all. The subsequent deviatoric response is almost identical to the intact behaviour. Note that, when the microstructural swelling is eliminated, the plastic shrinkage and swelling strains associated with the SD and SI yield loci are also zero, and they do not contribute to damage to the bonds.

Volumetric behaviour of Todi clay under two loadingunloading cycles

The behaviour of Todi clay was presented in Fig. 6. These results are a challenge to constitutive modelling because of the rather singular response of the soil. The initial loading response is quite rigid, a result that may be attributed mainly to the bonding response. Then the bond is damaged, and the soil expands substantially. However, upon reloading, once the bonding has essentially been destroyed, the material maintains a stiff behaviour, which has to be attributed to the clay matrix. These considerations helped in selecting the set of constitutive parameters given in Table 1, column 5 .

A more detailed interpretation of the test results, accepting the model developed as a suitable representation of the test, is now given. Reference is made to the numbers that identify the stress-strain response of the test (Fig. 18(a)). Initially (step 1-2) the stiffness of the existing bonds determines the response of the material. Damage starts at point 2, and it increases until point 4 . During the first unloading step (3-4) the rebound behaviour is defined by the elastic stiffness of matrix and the already highly damaged stiffness of the bond due to the previous loading path. At point 4, the yield surface SD is reached and an accumulated irreversible expansion is calculated. These plastic swelling strains explain the large recorded final void ratio when unloading is completed. The stress acting on the bonds is now very small. The state of damage at the end of the first loading-unloading cycle implies a new stress partition between matrix and bond. In fact, during the second cycle, the behaviour of the matrix component is dominant in the global response. During step 5-6 the SI yield surface is reached, but its effect in the compressibility of the matrix is small. Owing to the interaction defined between the LC and SI yield surfaces, and because during this second cycle the matrix component receives more load, the apparent preconsolidation stress is reduced and yielding conditions are reached at a low stress level (point 6). Beyond this point, the clay responds in an elasto-plastic manner following the matrix model. During the second unloading (step 7-9) the response is initially elastic, and the slope of the curve increases when the SD yield surface is reached again (point 8 ). In this case, the expansive potential of the material is lower because the stress point is now close to the current LC yield locus (lower overconsolidation ratio).

It is again interesting to compare the described response with the behaviour of a 'regular', non-expansive bonded material subjected to the same stress path, as in the previous case. The response is given in Fig. 18(b). The first compression steps $(1-2-3)$ are identical to the previous case. The 

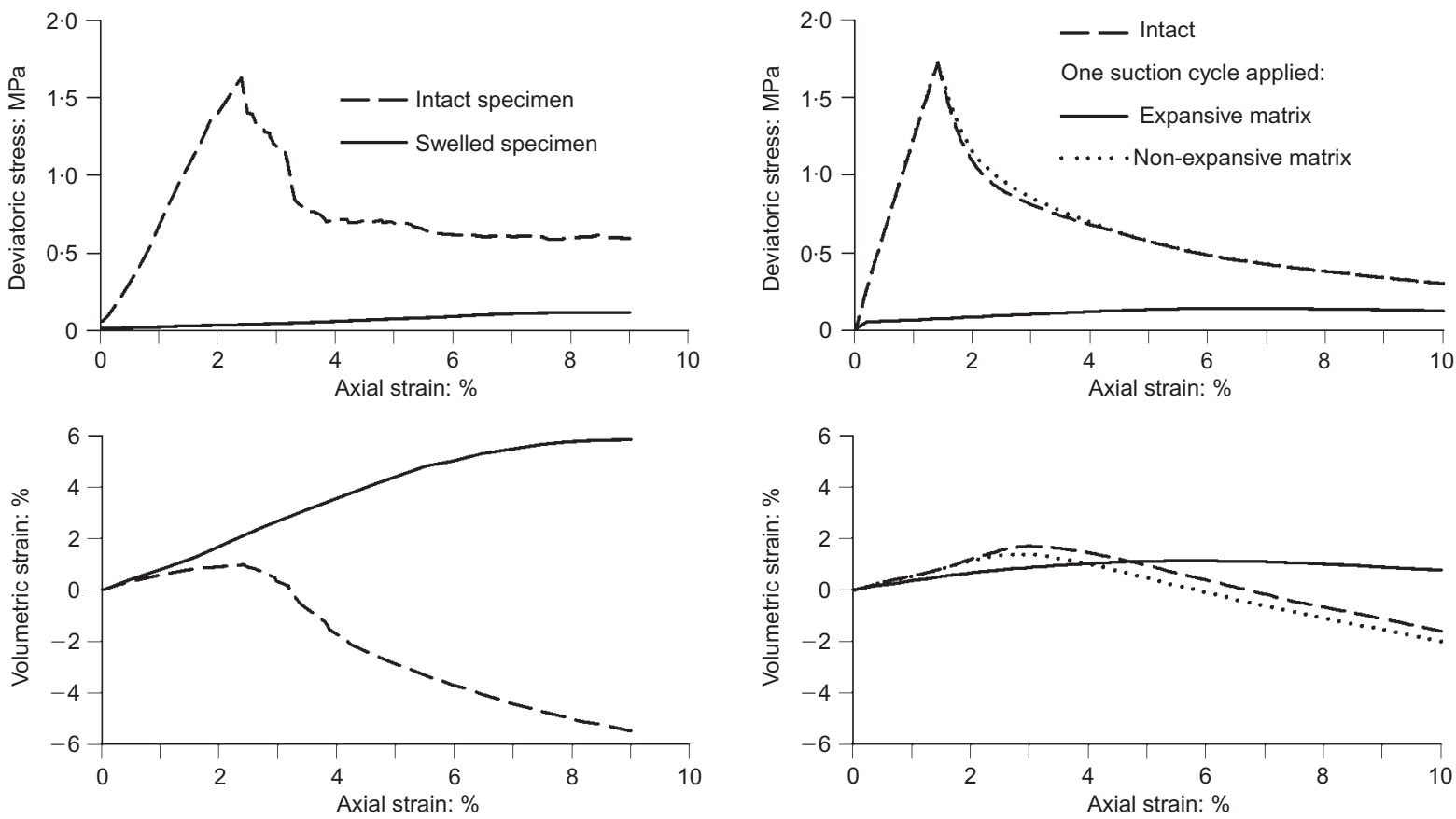

(a)

(b)

Fig. 17. Triaxial tests on La Biche shale: (a) experimental results (Wong, 1998); (b) computed results

bond also becomes damaged at point 2, and damage progresses thereafter. Upon unloading (3-4), the material follows the unloading stiffness, but it no longer yields (in expansion) at point 4 . The similarities between the two cases end here. The regular bonded material remains essentially elastic for the subsequent loading-unloading cycles.

\section{CONCLUSIONS}

Clay shales are commonly found in engineering works, and they are known in practice for the evolving nature of their mechanical properties. Stress changes, as well as environmental actions (notably the drying-wetting cycles experienced by the material exposed to atmospheric action), often lead to material degradation.

Two features are particularly relevant to explain the nature of weathering: the cementation of the clay matrix under stress, and the swelling/shrinkage behaviour of the clay aggregates when subjected to suction cycles. Both aspects are covered by the model presented in the paper.

Two constitutive models have been integrated into a common framework: an elasto-plastic model for expansive materials, and a damage model for the bond material. The integration follows some rules imposed by internal strain compatibility conditions. Stress partitioning between the two constituent materials (expansive clay matrix and bond) is achieved by means of the virtual work principle.

The resulting model has many features that appear to follow experimental observations. The stiff bond response explains the linear deviatoric stress-strain response often observed in triaxial tests before the peak strength is reached. Bond degradation contributes to the marked strain-softening observed after peak. The formulation ensures that the fully damaged material follows the behaviour of the clay matrix. A relevant feature of the model is the ability to incorporate damage induced by wetting and drying. This is a consequence of the elasto-plastic formulation of the clay matrix, which includes suction effects by means of a double-structure framework. The model is capable of reproducing the effect of cyclic drying-wetting, a fundamental aspect of weathering. When suction cycles are capable of irreversibly deforming the clay matrix, they may induce bond damage, which facilitates further straining. The material evolves towards new states characterised by decreasing strength, decreasing initial stiffness, increasing ductility and reduced dilatancy. These comments are illustrated in a few examples developed to show the capabilities of the model.

The ability of the model to achieve good quantitative results was shown by comparing model calculations with the reported response of two natural materials. One of the cases presented involved a comparison of the triaxial response of a shale, in both the unweathered and the fully weathered state (induced by full swelling when soaking the specimen in water). The two stress-suction paths were reproduced, and the calculated results were compared with the experiment. In a second case, the remarkable behaviour of an expansive structured clay subjected to a double loading-unloading cycle under oedometric conditions was reproduced.

More important than achieving a good representation of a given experiment, which typically requires a trial and error process in order to define a set of material parameters, is obtaining a set of consistent results for a variety of stress paths. In this sense, the developed model may help in gaining a more fundamental insight into the nature of weathering, an important practical aspect that is often approached in qualitative, descriptive and markedly empirical terms.

\section{ACKNOWLEDGEMENTS}

The authors wish to acknowledge the support provided by the Departament d'Educació í Universitats de la Generalitat de Catalunya and the European Social Fund during the development of the work reported in the paper.

$\begin{aligned} \text { NOTATION } & \\ C_{\mathrm{b}} & \text { band concentration } \\ D & \text { scalar damage variable } \\ e_{\mathrm{b}} & \text { void ratio of bonds } \\ e_{\mathrm{M}}^{*} & \text { void ratio of pores between clay aggregates } \\ e_{\mathrm{m}} & \text { void ratio of micropores } \\ e_{\mathrm{v}} & \text { void ratio of macropores }\end{aligned}$




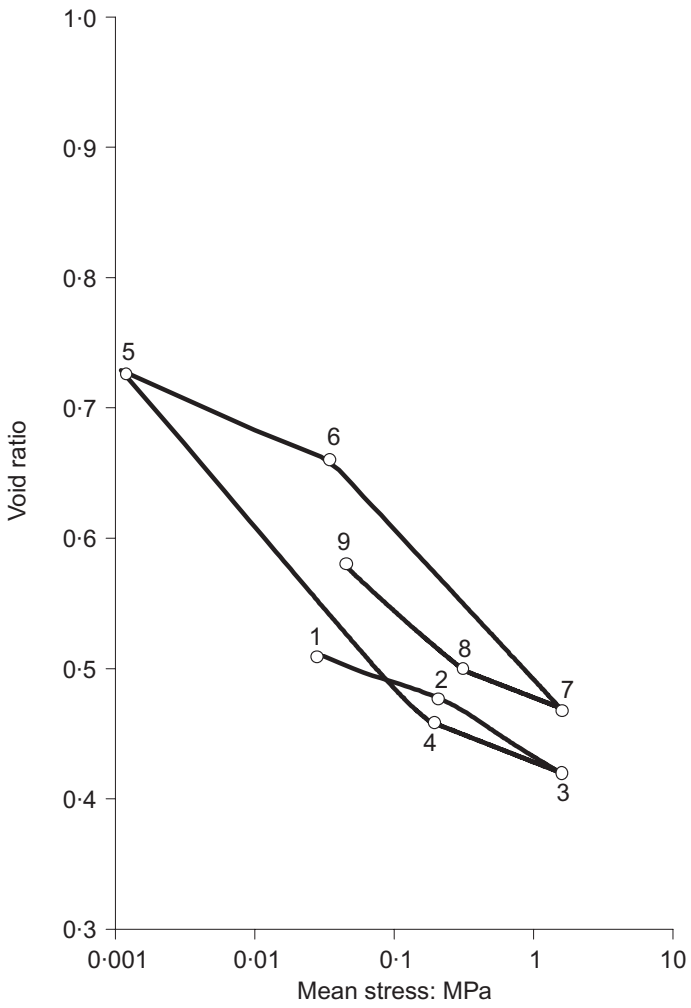

(a)

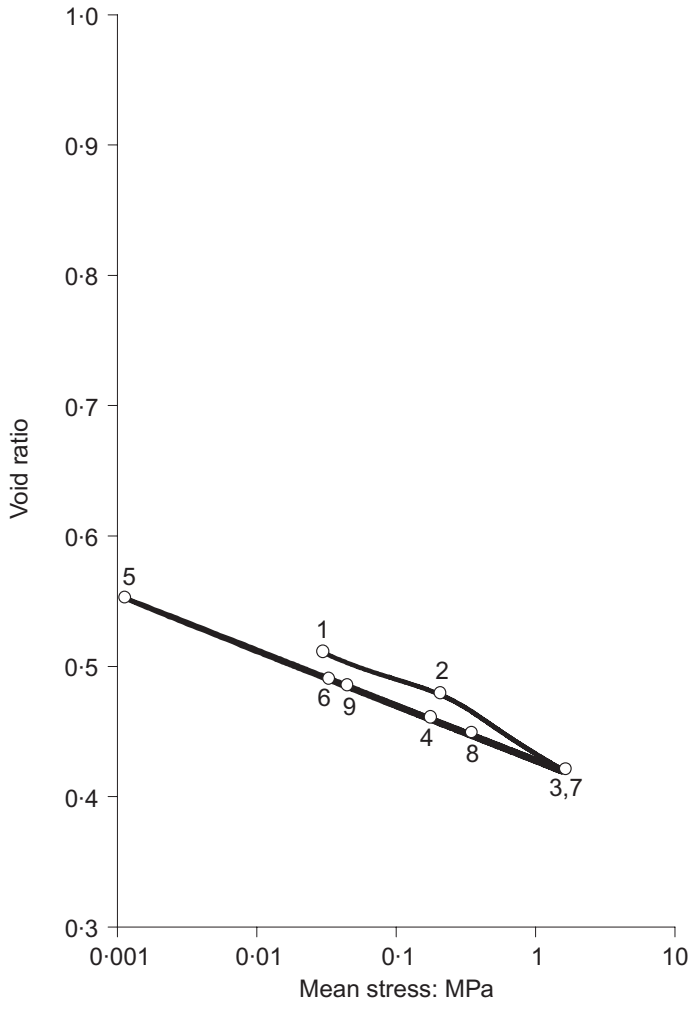

(b)

Fig. 18. Calculated response of Todi clay under two loadingunloading cycles: (a) expansive matrix; (b) non-expansive matrix

$f_{10}, f_{11}, n_{\mathrm{I}}$ parameters of micro-macro function when SI is active

$f_{\mathrm{D} 0}, f_{\mathrm{D} 1}, n_{\mathrm{D}}$ parameters of micro-macro function when $\mathrm{SD}$ is active

$G_{\mathrm{b}}$ bond shear modulus at current damage state for changes in bond deviatoric stress

$G_{\text {bext }}$ bond shear modulus at current damage state for changes in external mean stress in terms of external shear strain

$G_{\mathrm{b} 0}$ undamaged bond shear modulus for changes in bond deviatoric stress

$G_{\mathrm{M}}$ macro shear modulus (of arrangement of clay aggregates) for changes in matrix deviatoric stress

$G_{\text {Mext }}$ shear modulus of clay matrix (considering micro and macro effects) in terms of external shear strain

$K_{\mathrm{b}}$ bond bulk modulus at current damage state for changes in bond mean stress

$K_{\text {bext }}$ bond bulk modulus at current damage state for changes in external mean stress in terms of external volumetric strain

$K_{\mathrm{b} 0} \quad$ undamaged bond bulk modulus for changes in bond mean stress

$K_{\mathrm{M}}$ macro bulk modulus (of arrangement of clay aggregates) for changes in matrix mean stress

$K_{\mathrm{m}}$ micro bulk modulus (of clay aggregates) for changes in matrix mean stress

$K_{\text {Mext }}$ bulk modulus of clay matrix (considering micro and macro effects) in terms of external volumetric strain

$K_{\mathrm{s}}$ macro bulk modulus (of arrangement of clay aggregates) for changes in macro suction

$L$ logarithmic damage variable

$p_{0}^{\mathrm{M}} \quad$ mean yield stress at current suction

$p_{0}^{\mathrm{M}^{*}}$ mean yield stress for saturated conditions

$r_{0}$ initial damage state

$r_{1}$ bond damage rate

$s^{\text {macro }}$ macrostructural suction

$s^{\text {micro }}$ microstructural suction

$u_{\mathrm{b}} \quad$ secant elastic energy stored by bonds per unit of volume

$V$ total volume

$V_{\mathrm{b}}$ solid volume of bond material (assumed to be nonporous)

$V_{\mathrm{M}}^{*}$ volume between clay aggregates

$V_{\mathrm{m}}$ volume of micropores

$V_{\mathrm{s}}$ total volume of solids

$V_{\mathrm{sM}}$ solid volume of clay matrix

$V_{\mathrm{v}}$ volume of macropores

$\varepsilon^{\text {ext }} ; \varepsilon_{\mathrm{vol}}^{\mathrm{ext}}, \varepsilon_{\mathrm{q}}^{\mathrm{ext}}$ external strain; volumetric component, deviatoric component

$\varepsilon^{\mathrm{b}} ; \varepsilon_{\mathrm{vol}}^{\mathrm{b}}, \varepsilon_{\mathrm{q}}^{\mathrm{b}} \quad$ strain of bond; volumetric component, deviatoric component

$\varepsilon^{\mathrm{M}} ; \varepsilon_{\mathrm{vol}}^{\mathrm{M}}, \varepsilon_{\mathrm{q}}^{\mathrm{M}} \quad$ strain between aggregates; volumetric component, deviatoric component

$\varepsilon^{\mathrm{m}} ; \varepsilon_{\mathrm{vol}}^{\mathrm{m}} \quad$ strain of micropores; volumetric component

$\boldsymbol{\varepsilon}^{\mathrm{V}} ; \varepsilon_{\mathrm{vol}}^{\mathrm{V}}, \varepsilon_{\mathrm{q}}^{\mathrm{V}} \quad$ strain of macropores; volumetric component, deviatoric component

$\kappa$ elastic macro stiffness parameter for changes in mean stress

$\kappa_{\mathrm{m}}$ elastic micro stiffness parameter for changes in mean stress and micro suction

$\kappa_{\mathrm{s}}$ elastic macro stiffness parameter for changes in macro suction

$\boldsymbol{\sigma}^{\text {ext }}, p^{\text {ext }}, q^{\text {ext }}$ external stress, external mean stress, external deviatoric stress

$\boldsymbol{\sigma}^{\mathrm{M}}, p^{\mathrm{M}}, q^{\mathrm{M}}$ matrix stress, matrix mean stress, matrix deviatoric stress

$\sigma^{\mathrm{b}}, p^{\mathrm{b}}, q^{\mathrm{b}} \quad$ bond stress, bond mean stress, bond deviatoric stress

$\chi$ bonding deformation parameter

$\chi_{0}$ bonding deformation parameter associated with undamaged state

\section{REFERENCES}

Alonso, E. E., Gens, A. \& Josa, A. (1990). A constitutive model for partially saturated soils. Géotechnique 40, No. 3, 405-430.

Alonso, E. E., Vaunat, J. \& Gens, A. (1999). Modelling the mechanical behaviour of expansive clays. Engng Geol. 54, Nos 1-2, $173-183$.

Alonso, E. E. \& Berdugo, I. (2005). Expansive behaviour of sulphate-bearing clays. Proceedings of the international conference on problematic soils, Famagusta, pp. 1-25 
Bertuccioli, P. \& Lanzo, G. (1993). Mechanical properties of the Italian structurally complex clay soils. Proc. Symp. Geotech. Engng Hard Soils-Soft Rocks, Athens, 383-389.

Bjerrum, L. (1967). Progressive failure in slopes of overconsolidated plastic clay and clay shales. J. Soil Mech. Found. Div. ASCE 93, No. SM5, 3-49.

Calabresi, G. \& Scarpelli, G. (1985). Effects of swelling cause by unloading in overconsolidation clays. Proc. 11th Int. Conf. Soil Mech. Found. Engng, San Francisco 1, 411-414.

Carol, I., Rizzi, E. \& Willam, K. (2001) On the formulation of anisotropic elastic degradation. I. Theory based on a pseudologarithmic damage tensor rate. Int. J. Solids Struct. 38, No. 4, $91-518$.

Fernández, A. \& Santamarina, C. (2001). The effect of cementation on the small strain parameters of sand. Can. Geotech. J. 38, No. 1, 191-199.

Gens, A. \& Alonso, E. (1992). A framework for the behaviour of unsaturated expansive clays. Can. Geotech. J. 29, No. 6, 1013-1032.

Hsu, S. C. \& Nelson, P. P. (1993). Characterization of Cretaceous clay shales in North America. Proc. Symp. Geotech. Engng Hard Soils-Soft Rocks, Athens 1, 139-146.

Kavvadas, M. J. (2000). General report. Modelling the soil behaviour: selection of soil parameters. Proc. 2nd Int. Symp. Geotech. Hard Soils-Soft Rocks, 2, 1441-1481.
Mitchell, J. K. (1976). Fundamentals of soil behaviour. New York: Wiley.

Olivier, H. J. (1987). Some aspects of the influence of mineralogy and moisture redistribution on the weathering behaviour of mudrock. Proc. 4th Int. Conf. Rock Mech., Montreaux, 3, 467-474.

Picarelli, L. (1991). Discussion: 'The general and congruent effects of structure in natural soils and weak rocks' by S. Leroueil \& P. R. Vaughan. Géotechnique 40, No. 2, 281-284.

Pye, K. \& Krinsley, D. H. (1983). Interlayered clay stacks in Jurassic shales. Nature 304, No. 5927, 618-620.

Rampello, S. (1991). Some remarks on the mechanical behaviour of stiff clays: the example of Todi clay. Proceedings of the international workshop on experimental characterization and modelling of soils and soft rocks, Napoli, pp. 131-190.

Sanmartino, S. (2001). Construction d'un modèle conceptuel de la porosité et de la minéralogie dans les argiles du site de Bure. Internal report D.RP.OCPE.03. 001, Paris: ANDRA.

Seedsman, R. W. (1987). Strength implications of the crystalline and osmotic swelling of clays in shales. Int. J. Rock Mech. Min. Sci. Geomech. Abstr. 24, No. 6, 357-363.

Vaunat, J. \& Gens, A. (2003). Bond degradation and irreversible strains in soft argillaceous rock. Proc. 12th Panam. Conf. Soil Mech. Geotech. Engng, Boston 1, 479-484.

Wong, R. C. K. (1998). Swelling and softening behaviour of La Biche shale. Can. Geotech. J. 35, No. 2, 206-221. 